\title{
THM-coupled finite element analysis of frozen soil: formulation and application
}

\author{
S. NISHIMURA*, A. GENS $\dagger$, S. OLIVELLA ${ }^{\star}$ and R. J. JARDINE
}

\begin{abstract}
A fully coupled thermo-hydro-mechanical (THM) finite element (FE) formulation is presented that considers freezing and thawing in water-saturated soils. The formulation considers each thermal, hydraulic and mechanical process, and their various interactions, through fundamental physical laws and models. By employing a combination of ice pressure, liquid pressure and total stress as state variables, a new mechanical model has been developed that encompasses frozen and unfrozen behaviour within a unified effective-stress-based framework. Important frozen soil features such as temperature and porosity dependence of shear strength are captured inherently by the model. Potential applications to geotechnics include analysis of frost heave, foundation stability or mass movements in cold regions. The model's performance is demonstrated with reference to the in situ pipeline frost heave tests conducted by Slusarchuk et al. Detailed consideration is given to $\mathrm{FE}$ mesh design, the influence of hydraulic parameters, and the treatment of air/ground interface boundary conditions. The THM simulation is shown to reproduce, with fair accuracy, the observed pipeline heave and the porosity growth driven by water migration.
\end{abstract}

KEYWORDS: ground freezing; numerical modelling; temperature effects; water flow
Dans la présente communication, on présente une formulation aux éléments finis thermo-hydro-mécanique (THM) à accouplement intégral, pour l'examen du gel et du dégel dans des sols saturés d'eau. La formulation examine chaque processus thermique, hydraulique et mécanique, et leurs différentes interactions, par le biais de lois et modèles physiques fondamentaux. En employant une combinaison de pression de la glace, de pression liquide, et de contrainte totale comme variables d'état, on développe un nouveau modèle mécanique incorporant un comportement congelé et non congelé, dans un cadre effectif unifié à base de contrainte. Le modèle permet de capturer d'importantes propriétés des terrains congelés, comme la mesure dans laquelle la résistance au cisaillement est tributaire de la température et de la porosité. Parmi les applications potentielles dans la géotechnique, indiquons l'analyse du foisonnement par le gel, la stabilité des fondations, ou les mouvements de masse dans des régions froides. Les performances du modèle sont démontrées relativement aux tests de foisonnement par le gel in situ sur le pipeline, effectués par Slusarchuk et al. On examine en détail l'étude maillée aux EF, l'influence de paramètres hydrauliques, ainsi que le traitement des conditions limites de l'interface air/sol. On démontre, avec un bon degré de précision, que la simulation THM reproduit le foisonnement relevé sur le pipeline ainsi que l'augmentation de la porosité déterminée par la migration de l'eau.

\section{INTRODUCTION}

Freezing and thawing of pore fluid within soils involves complex thermal, hydraulic and mechanical processes that can have significant mutual geotechnical interactions. For example, phase changes of pore fluid caused by temperature variations modify the hydraulic regime of the soil, which in turn induces mechanical deformation. At the same time, any change in the hydraulic and mechanical conditions feeds back to the thermal processes by way of advection and changes in ice and water contents. Such thermo-hydro-mechanical (THM) interactions underlie many cold-region geomorphological processes, such as solifluction and thermokarst formation, as well as geotechnical problems, such as frost heaving, foundation distress/settlement and slope instability.

Analysis of frozen soils' THM-coupled behaviour inevita-

Manuscript received 8 May 2008; revised manuscript accepted 21 November 2008

Discussion on this paper closes on 1 September 2009, for further details see p. ii.

* Geotechnical and Structural Engineering Department, Port and Airport Research Institute, Japan; formerly Department of Civil and Environmental Engineering, Imperial College London, UK.

$\dagger$ Department of Geotechnical Engineering and Geosciences, Universitat Politècnica de Catalunya, Spain.

\$Department of Civil and Environmental Engineering, Imperial College London, UK. bly requires a numerical technique such as the finite element method (FEM), owing to the non-linearity of the governing equations, and their reciprocal coupling. Models have been developed and implemented with differing degrees of sophistication, depending on their particular application purposes. However, a solid framework has yet to be established for fully coupled THM approaches. Historically, most geotechnical analyses of frozen soils adopted total-stress-based mechanical treatments (e.g. Ladanyi, 1972, 1975; Ladanyi \& Johnston, 1974; Nixon, 1978; Jessberger, 1981; Andersland \& Ladanyi, 2004), sometimes combined with uncoupled thermal analysis (e.g. Nixon, 1990). Total-stress treatments have continued to be adopted in more recently proposed models (e.g. He et al., 1997; He \& Cheng, 2000; Arenson \& Springman, 2005).

Parallel efforts to simulate mass and heat transfer problems in freezing and thawing soils have led to almost independent developments in TH-coupled models, often focusing on frost heave analysis, for which three main streams of development can be identified:

(a) rigid-ice models (e.g. Miller, 1978; Gilpin, 1980; O’Neill \& Miller, 1985; Nixon, 1991; Nakano, 1997)

(b) hydrodynamic models (e.g. Harlan, 1973; Guymon \& Luthin, 1974; Jame \& Norum, 1980; Newman \& Wilson, 1997; Hansson et al., 2004; Hansson \& Lundin, 2006)

(c) the segregation potential model (Konrad \& Morgenstern, 1980, 1981, 1984). 
Their principles and characteristics are discussed, for example, by Kujala (1997). A common feature of TH-coupled models is their lack of an explicit formulation for the mechanical behaviour of the soil skeleton. In hydrodynamic models, mechanical equilibrium is usually not considered. In the other two approaches, the soil skeleton stresses are only implicitly invoked in the particle segregation criteria. When shear stresses and soil deformation play a significant role, as in many boundary value problems, an independent treatment is required outside the TH-coupled framework. Carlson \& Nixon's (1988) pipeline frost heave treatment is one such example discussed later in this paper.

Mechanical terms that reproduce the failure/deformation of frozen ground have been incorporated explicitly into fully coupled THM models (Blanchard \& Fremond, 1985; Li et al., 2000, 2002) and semi-coupled THM formulations (Selvadurai et al., 1999a, 1999b). Fully coupled THM formulations based upon fundamental physics provide unified models that reproduce both the failure/deformation and the coupled heat/mass transfer in frozen ground, which conventionally have been treated in separate ways. In order to complete this integration, the mechanical constitutive model for frozen soils must have continuity with the effective-stress constitutive models applied to unfrozen soils. Most boundary value problems involve both states, and transient moving boundaries between them. The architecture of such models does not appear to be well established.

The following sections outline a fully coupled THM FEM framework and a new critical-state elasto-plastic mechanical soil model developed to consider problems involving frozen and unfrozen soil. Quantitative evaluation is demonstrated

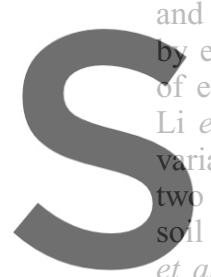
examining frost-heave process existing THM formulations et al., 2000, 2002) that adopt riable (Bishop \& Blight, stress variables, following thr mechanics (e.g. Fredlund \& I. 1990; Fredlund, 2000)
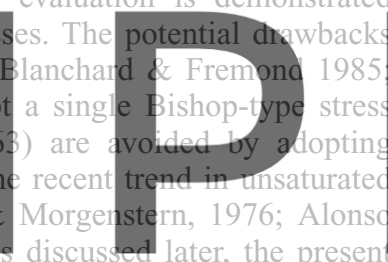

model has limitations in describing some frozen soil fea-

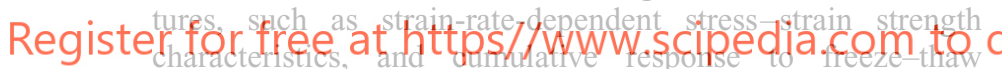
cycles. However, the proposed framework should allow future incorporation of effective-stress-based formulations that can reproduce such features in unfrozen soils.

In the final part of the paper, the proposed THM model is verified against a series of in situ frost heave tests conducted by Slusarchuk et al. (1978) involving a chilled pipeline. Issues relating to numerical implementation are discussed, including mesh conditioning, assessment of hydraulic parameter influence, and prescription of surface thermal boundary conditions. This study, in conjunction with a geographically broader approach (Nishimura et al., 2009), formed part of a multidisciplinary Imperial College project funded by $\mathrm{BP}$ that investigated possible climate change impacts on cold region infrastructure (Clarke et al., 2008).

\section{GOVERNING EQUATIONS}

The frozen soil formulation presented builds from the THM modelling by Olivella et al. $(1994,1996)$ and Gens et al. (1998) of high-temperature problems involving a gas phase. Low-temperature problems can be considered with the same overall structure if the original gas phase is replaced by a new solid phase representing ice. For simplicity, no gaseous phase (undersaturation) or dissolved salt is considered at present. The formulation has been implemented in the FEM code CODE_BRIGHT (Olivella et al., 1996), and we consider below the new features required to address freeze/thaw conditions.

\section{Thermodynamic equilibrium of freezing soil}

The equilibrium between liquid water and ice phases is described by the Clausius-Clapeyron equation, derived from equilibrium of the chemical potentials between two phases. This equation is expressed as

$$
-\left(s_{1}-s_{2}\right) \mathrm{d} T+v_{1} \mathrm{~d} P_{1}-v_{2} \mathrm{~d} P_{2}=0
$$

where $s$ and $v$ are the specific entropy and the specific volume respectively, $T$ is temperature on the thermodynamic scale, and $P$ is pressure (e.g. Henry, 2000). Subscripts 1 and 2 refer to each of two different phases/materials in equilibrium. When applied to equilibrium between pure ice and liquid water,

$$
-\left(s_{1}-s_{\mathrm{i}}\right) \mathrm{d} T+v_{1} \mathrm{~d} P_{1}-v_{\mathrm{i}} \mathrm{d} P_{\mathrm{i}}=0
$$

or

$$
\mathrm{d} P_{\mathrm{i}}=\frac{\rho_{\mathrm{i}}}{\rho_{1}} \mathrm{~d} P_{1}-\frac{\rho_{\mathrm{i}} l}{T} \mathrm{~d} T
$$

where $l$ is the specific latent heat of fusion, $\rho(=1 / v)$ is the mass density, and the subscripts 1 and $i$ refer to liquid water and ice respectively. This differential form can be integrated using atmospheric pressure and the temperature $273 \cdot 15 \mathrm{~K}$ as references, to give

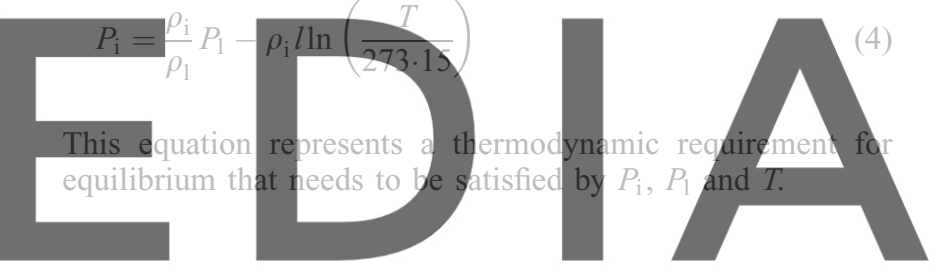

Freezing characteristic function

The modelling requires a freezing characteristic function
(= volume of liquid phase/volume of pore) to the soil's thermodynamic properties. Many researchers have developed freezing characteristic functions through analogies with water retention models developed to describe the drying and wetting of unsaturated unfrozen soils, where gas and liquid phases coexist in the pores (e.g. Koopmans \& Miller, 1966; Miller, 1978; Black \& Tice, 1989; Grant \& Sletten, 2002; Coussy, 2005). The different pressures between the liquid water and ice phases expressed by the Clausius-Clapeyron equation (equation (4)) suggest that surface tension forces should develop along the interface between the two phases, as illustrated in Fig. 1. The freezing characteristics and the water retention characteristics are both determined by the soil pore size distribution (e.g. Fredlund \& Xing, 1994; Coussy, 2005) and the interface tension force. It is therefore natural to assume that the two functions can be expressed by similar forms of equation, once allowance is made for the difference between the ice/liquid and gas/liquid interface tension forces. The van Genuchten (1980) model was employed here to represent the freezing characteristic function,

$$
S_{1}=\left[1+\left(\frac{P_{\mathrm{i}}-P_{1}}{P}\right)^{\frac{1}{1-\lambda}}\right]^{-\lambda}
$$

where $P$ and $\lambda$ are material constants. This equation represents the relationship between $P_{\mathrm{i}}, P_{1}$ and $S_{1}$. The generally hysteretic nature of soil freezing characteristic (e.g. Williams, 1964) is not considered in this study. 


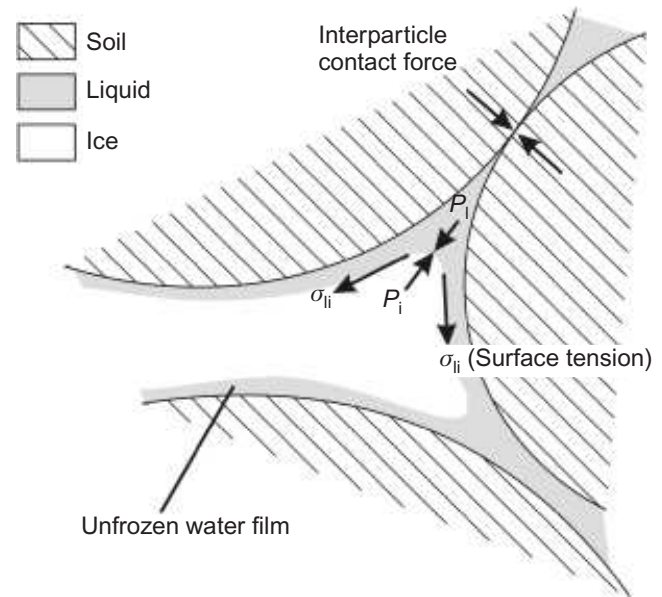

Fig. 1. Micro-configuration of phases in frozen soil

By combining equations (4) and (5), the freezing characteristic function relating $S_{1}$ to $T$ can be obtained as

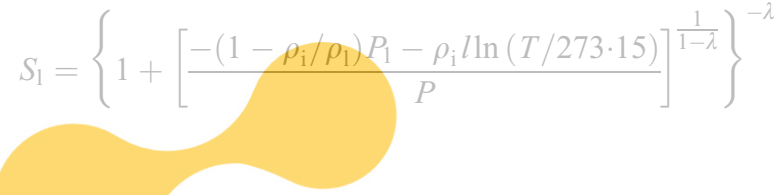

Equation (6) accounts explicitly for the liquid pressure $P_{1}$, unlike other commonly used empirical expressions such as $w_{\mathrm{u}}=\alpha\left|T-T_{\mathrm{f}}\right|^{\beta}$ (where $\alpha, \beta$, and $T_{\mathrm{f}}$ are material properties) that relate the unfrozen water content $w_{11}$ to temperature, $T$

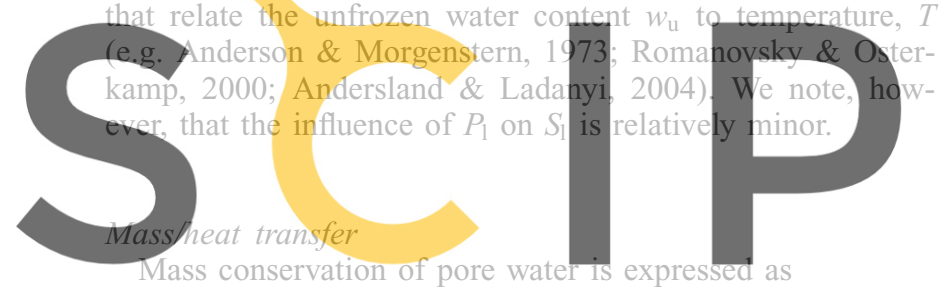

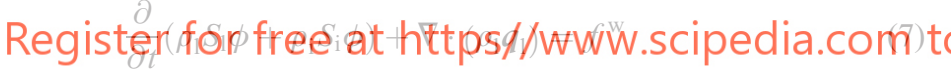

where $\phi$ is the porosity; $S_{1}$ and $S_{1}$ are degrees of liquid and ice saturation respectively $\left(S_{1}+S_{1}=1\right.$, as neither a gas phase nor cavitation is considered); $\boldsymbol{q}_{1}$ is the liquid water flux vector; and $f^{\mathrm{w}}$ is the sink/source term of mass. The water flux is calculated from generalised Darcy's law as

$$
\boldsymbol{q}_{1}=-\frac{k_{\mathrm{r}}}{\mu_{1}}[k]\left(\nabla P_{1}-\rho_{1} \boldsymbol{g}\right)
$$

where $\boldsymbol{g}$ is the gravity acceleration vector, $[k]$ is the intrinsic permeability matrix, $\mu_{1}$ is the viscosity of liquid water, and $k_{\mathrm{r}}$ is the liquid phase relative permeability. Viscosity can be considered a function of the temperature, as

$$
\mu_{1}=2 \cdot 1 \times 10^{-6} \exp \left(\frac{1808 \cdot 5}{273 \cdot 15+T}\right) \quad(\mathrm{Pa} \times \mathrm{sec})
$$

Relative permeability can be calculated from the expression

$$
k_{\mathrm{r}}=\sqrt{S_{1}}\left[1-\left(1-S_{1}^{1 / \lambda}\right)^{\lambda}\right]^{2}
$$

which can be derived from the van Genuchten function (equation (5)). The parameter $\lambda$ is a material constant that in principle coincides with that used in the retention curve (equation (5)), and $k_{\mathrm{r}}$ varies between 0 and 1 . The intrinsic permeability in the generalised Darcy's equation and the hydraulic conductivity $[K]$ (usually used in the flow equation when written in terms of piezometric head) are related by

$$
[K]=\frac{\rho_{1} g}{\mu_{1}}[k]
$$

For reference, the relationship between the hydraulic conductivity and intrinsic permeability for water at a temperature of $20^{\circ} \mathrm{C}$ is: $[K](\mathrm{m} / \mathrm{s})=[k]\left(\mathrm{m}^{2}\right) \times 1000\left(\mathrm{~kg} / \mathrm{m}^{3}\right) \times$ $9.81(\mathrm{~N} / \mathrm{kg}) / 10^{-3} \mathrm{Pas}=9.8 \times 10^{6}(1 / \mathrm{m} \mathrm{s}) \times[k]\left(\mathrm{m}^{2}\right) . \mathrm{In}$ the present study, permeability is considered isotropic.

The energy conservation equation is written as

$$
\begin{aligned}
& \frac{\partial}{\partial t}\left[e_{\mathrm{s}} \rho_{\mathrm{s}}(1-\phi)+e_{\mathrm{l}} \rho_{1} S_{1} \phi+e_{\mathrm{i}} \rho_{\mathrm{i}} S_{\mathrm{i}} \phi\right] \\
& +\nabla \cdot\left(-\lambda \nabla T+\mathbf{j}_{1}^{\mathrm{e}}\right)=f^{\mathrm{e}}
\end{aligned}
$$

where $e_{\mathrm{s}}, e_{1}$ and $e_{\mathrm{i}}$ are the specific internal energy of solid soil minerals, liquid water and ice respectively; $\lambda$ is in this case the overall thermal conductivity of the soil mass (consisting of soil minerals and pore materials); $\boldsymbol{j}_{1}^{\mathrm{e}}$ is the advective term of heat flux $\left(\boldsymbol{j}_{1}^{\mathrm{e}}=e_{1} \rho_{1} \boldsymbol{q}_{1}\right)$; and $f^{\mathrm{e}}$ is the sink/ production term of energy. Fourier's law is employed in the above equation for calculating the conductive heat flux. The overall thermal conductivity $\lambda$ is calculated by using the geometric mean (Côté and Konrad, 2005),

$$
\lambda=\lambda_{\mathrm{s}}^{1-\phi} \lambda_{\mathrm{l}}^{S_{\mathrm{l}} \phi} \lambda_{\mathrm{i}}^{\left(1-S_{\mathrm{l}}\right) \phi}
$$

where the subscript $\mathrm{s}$ denotes the soil mineral phase. The specific internal energies, $e_{\mathrm{S}}, e_{1}$ and $e_{\mathrm{i}}$, are
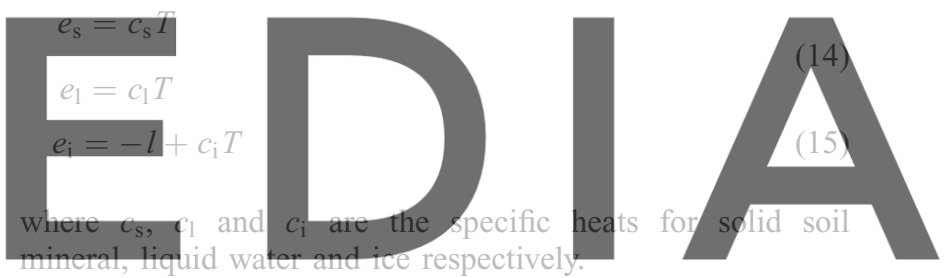

\section{dewnilgad the version without the watermark \\ Mechanical equilibrium can be written as \\ $\nabla \cdot \sigma+b=0$

where $\boldsymbol{\sigma}$ are total stresses and $\boldsymbol{b}$ are body forces.

\section{MECHANICAL CONSTITUTIVE MODEL FOR FROZEN AND UNFROZEN SOIL}

Some researchers have proposed using a single Bishoptype stress variable (Bishop \& Blight, 1963),

$$
\boldsymbol{\sigma}_{\mathrm{b}}=\boldsymbol{\sigma}-\chi P_{1}[\boldsymbol{I}]-(1-\chi) P_{\mathrm{i}}[\boldsymbol{I}]
$$

([I] is the unit matrix), when defining constitutive relationships for frozen soils linking stress $\boldsymbol{\sigma}$ and strain $\varepsilon$ (see Miller, 1978, or Li et al., 2002), considering that the term $\boldsymbol{\sigma}_{\mathrm{b}}$ provides an equivalent effective stress for frozen soils. The parameter $\chi$ is sometimes assumed to be equal to the degree of liquid saturation, $S_{1}$. However, an inexpedient aspect of its use is that, if the soil skeleton is very loose and ice pressure takes the major part of the total stress, $\boldsymbol{\sigma}_{\mathrm{b}}$ becomes close to zero. If $\boldsymbol{\sigma}_{\mathrm{b}}$ alone is used, conventional effective-stress-based failure criteria developed for unfrozen soils (for example Mohr-Coulomb) predict very low shear strength, whereas ice-rich loose frozen soils tend to have relatively high short-term shear strength. One approach to overcome this problem is to develop failure criteria that are dependent on another variable, or combination of variables.

Noting the close analogy between the physics of frozen- 
saturated and unfrozen-unsaturated soils, this study adopted an alternative two-stress variable constitutive relationship (see Fredlund \& Morgenstern, 1976; Alonso et al., 1990; Fredlund, 2000; Gens et al., 2006; Gens, 2007). Adopting stress variables $p_{\mathrm{n}}=p-\max \left(P_{1}, P_{\mathrm{i}}\right)$ and $s=\max \left(P_{\mathrm{i}}-\right.$ $\left.P_{1}, 0\right)$ (in addition to the deviatoric stress $q$ ) allows the Barcelona Basic Model (the BBM; Alonso et al., 1990) developed for unsaturated soil to be extended to provide a new constitutive model that describes the essential features of frozen and unfrozen behaviour. The variables $p_{\mathrm{n}}$ and $s$ can be interpreted as the net stress representing external confinement and the suction respectively. The yield surface is expressed as

$$
F=\left[p_{\mathrm{n}}-\left(\frac{p_{\mathrm{n} 0}-k s}{2}\right)\right]^{2}+\frac{q^{2}}{M^{2}}-\left(\frac{p_{\mathrm{n} 0}+k s}{2}\right)^{2}
$$

where

$$
q=\sqrt{\frac{3}{2}\left(s_{i j} \cdot s_{i j}\right)}, \quad s_{i j}=\sigma_{i j}-p \delta_{i j}
$$

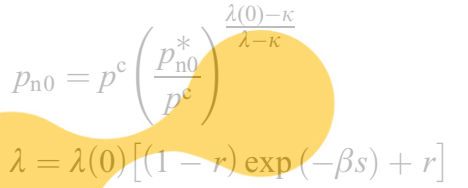

and $M, k, \lambda(0), \kappa, p^{\mathrm{c}}, \beta$ and $r$ are constants; see Alonso et al. (1990) for details.

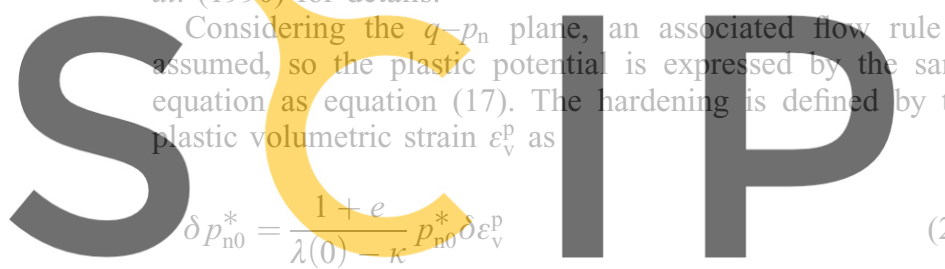

where $e$ is the void ratio. The yield surface defined by the

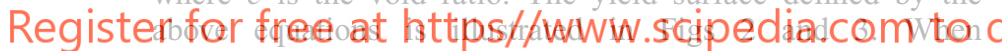
unfrozen (i.e. $s=0$ ), the model reduces to an effective stress-based critical state model similar to Modified CamClay (Roscoe \& Buriand, 1968, or Wood, 1990). As temperatures fall below the freezing point, $s$ increases and the yield surface cross-section in the $q-p_{\mathrm{n}}$ plane expands, giving the soil higher yield stress and strength. Some of the original BBM features remain unactivated, such as the influence of $s$ on $\kappa$, the elastic volumetric changes caused by changes in $s$, and the SI surface (a 'cap' yield surface parallel to the $q-p_{\text {n }}$ plane). However, these features could be readily incorporated in cases where they are considered relevant.

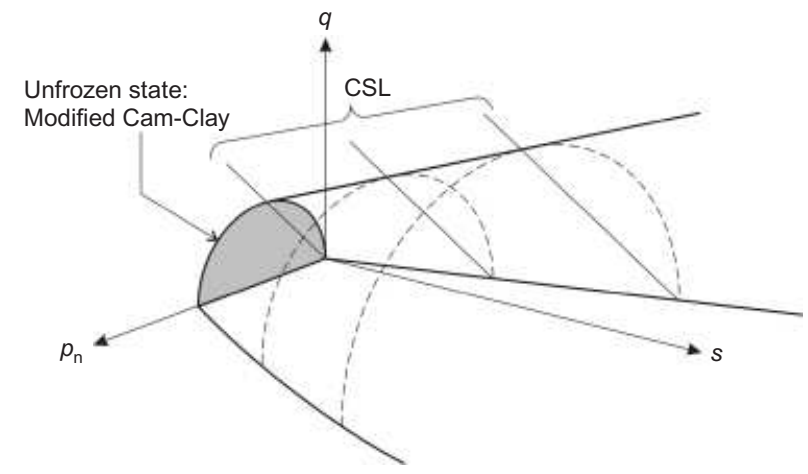

Fig. 2. Three-dimensional view of yield surface of the constitutive model for frozen soils

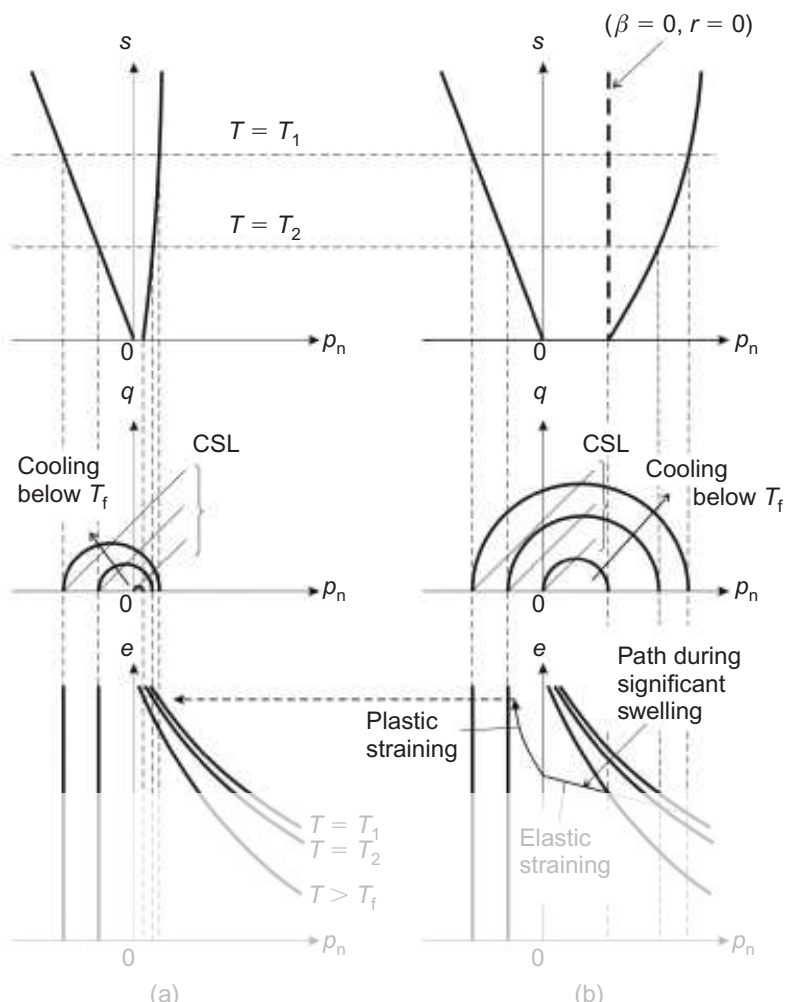

(b)

Fig. 3. Projections of yield surface of the constitutive model for frozen soils. $T_{1}$ and $T_{2}$ are arbitrary temperatures below the freeze point $T_{\mathrm{f}}$ such that $T_{1}<T_{2}<T_{\mathrm{f}}$ : (a) ice-rich soil; (b) ice-
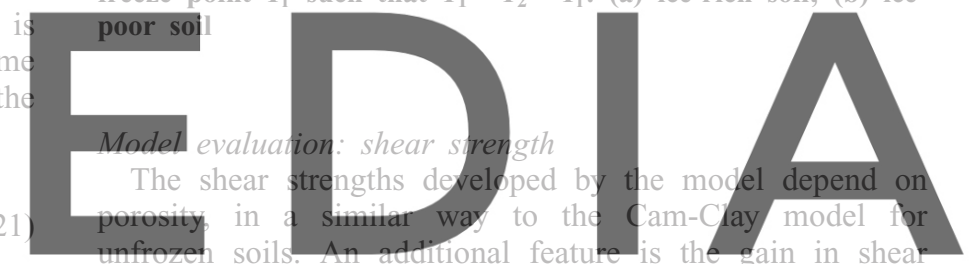

strength with ice content which grows as the 'suction'

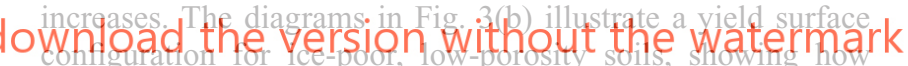
the yield surface associated with the colder, frozen soil grows beyond that applying to the unfrozen state. The expansion of the yield surface in the $q-p_{\mathrm{n}}$ plane during cooling (which coincides with increasing $s$ ) involves both enhanced particle interlocking (expansion towards the right) and ice strengthening (expansion towards the left). In a physical sense, the latter is considered to induce the former through increased internal confinement, as suggested by Ladanyi \& Morel (1990). With ice-rich, high-porosity soils, as illustrated in the diagrams in Fig. 3(a), the coolinginduced expansion of the yield surface cross-section is dominantly in the leftward direction, indicating the importance of the ice strength. The modelling mechanisms provide logical descriptions of frozen soils' porosity-dependent strength.

Early experimental work by Goughnour \& Andersland (1968) demonstrated that the peak shear strength of frozen Ottawa Sand decreases as the porosity increases, tending towards the strength of pure ice when the porosity reaches $100 \%$. Fig. 4 compares their findings with the trends for schematic shear strength (shear stress at the critical state) predicted by the proposed model. As mentioned earlier, the strain-rate-dependent nature of frozen soil is not considered at this stage.

A series of single-element FEM simulations was run to confirm the model's performance in triaxial compression. The input parameter values used here, shown in Fig. 5, are the same as those used in the two-dimensional simulation 


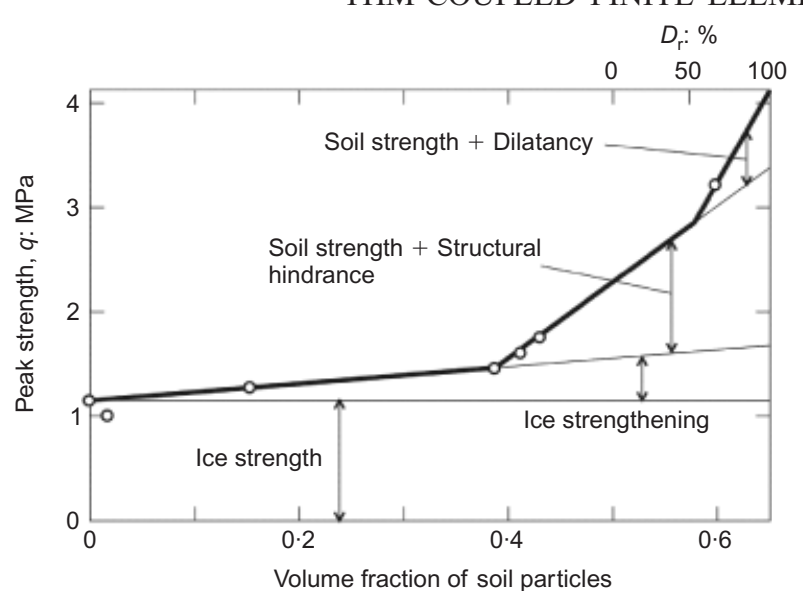

(a)

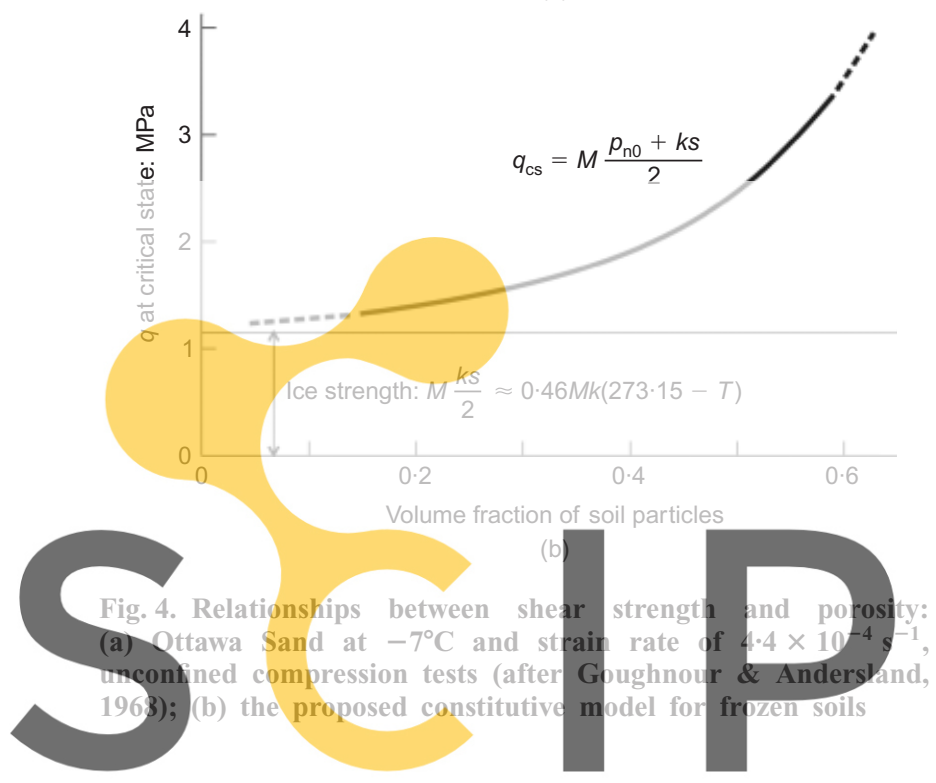

presented later. The initial stress condition was isotropic at

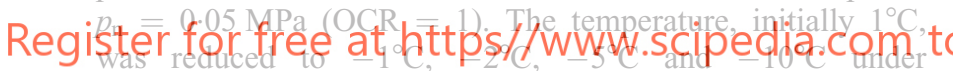
undrained conditions, and then undrained triaxial compression was simulated. The stress-strain relationships and the stress paths are shown in Fig. 5. Higher shear strength was predicted at lower temperature, as reported experimentally (e.g. Parameswaran, 1980; Bragg \& Andersland, 1981; Ouvry, 1985; Shibata, 1985; Sayles, 1988; Wang et al., 2004). Note that $\beta$ and $r$, the parameters that control the yield surface expansion along the $s$-axis, were set to zero owing to a lack of suitable information for determining them; the top-right diagram in Fig. 3 presents the resultant yield surface shape. This simplification had limited consequences, as the stress paths engaged only the dry side of the yield surface.

Model evaluation: freeze-thaw cycles

In the conventional Cam-Clay model, the elastic volumetric behaviour is non-linear, with a bulk modulus $K$ given by $K=\left(1+e_{0}\right) p^{\prime} / \kappa$. In the present model, however, $K$ is assumed to be linear, given by $K=E / 3(1-2 v)$. It follows that $p_{\mathrm{n}}$ can become zero or negative as the void ratio increases, unlike Modified Cam-Clay simulations, representing a state in which soil particles are segregated owing to excessive inflow of water (see Fig. 3).

Unloading and reloading are neither linear in real soils, as in the presented model, nor logarithmically linear, as in the Cam-Clay model. More sophisticated functions may be adopted if considered necessary.
A simple example of undrained freezing-thawing cycles under constant isotropic total stress is considered below to illustrate some of the advantages and limitations of the present formulation. The volumetric strain of soil caused by the (approximately 9\%) expansion of pore water on freezing is a function of porosity $\phi$, and is denoted here as $\Delta \varepsilon_{\mathrm{we}}$. When freezing initiates from a relatively high stress, such as point A in Fig. 6(b), the predicted volume $-p_{\text {n }}$ path follows a closed loop (loop A-B), and no thaw consolidation occurs under constant $p$. In contrast, when the volumetric-stress path engages the yield surface during volume expansion from a low initial stress, such as point $\mathrm{C}$ in Fig. 6(b), part of the expansion is accommodated by plastic volumetric straining, resulting in a softening that reduces $p_{\mathrm{n} 0}$ between points A and E. Elastic models would predict a considerable tensile stress as the volumetric strain increases, which would impede further inflow of water. Whereas such a mechanism may be relevant to well-cemented geomaterials, such resistance against water inflow should be minimal in uncemented soils. The elasto-plastic features in the model are effective in reproducing the likely behaviour of the soil skeleton during loosening/segregation. If the freezing induces significant swelling, as in frost heave phenomena, the state path follows the trend indicated in the bottom diagram in Fig. 3(b), and reaches a high final porosity. Since the model is volumetrically hardening, this swelling results in shrinkage of the yield surface cross-section in the positive $p_{\mathrm{n}}$ domain: compare the middle diagram in Fig. 3(a) with that in Fig. 3(b).

Further elaboration of the model is required to capture

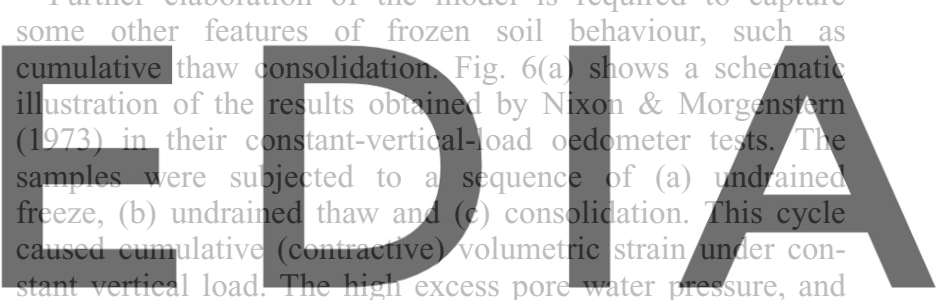

hence the low effective stress, developed at the end of the

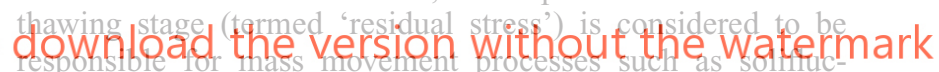
tion. This feature, which is beyond the scope of this paper, could be addressed by applying approaches similar to those developed with critical state models to reproduce realistic cyclic loading responses within the main yield locus.

\section{APPLICATION OF THM ANALYSIS TO FROST HEAVE PREDICTION \\ Background and problem setting}

The performance of the THM model and its numerical implementation were evaluated with reference to published pipeline frost heave experiments. Frost heave refers to ground expansion caused by water migration and accumulation in a frozen fringe (i.e. a transitional zone just behind a freezing front, where soil is partially frozen). The water migration is driven by cryogenic suction (represented by equation (5)) but at the same time is impeded by the reduced permeability developed in partially frozen soil. This phenomenon is most pronounced in silty soils, in which moderate to strong suction can be generated while retaining relatively high permeability. Frost heave is of particular concern in highway and pipeline engineering.

A benchmark series of in situ tests conducted by Slusarchuk et al. (1978) in Calgary allow the model to be evaluated. Trenches were made in permafrost-free silty ground and full-scale $1.22 \mathrm{~m}$ diameter steel pipelines were installed, with the original soil being placed as backfill. Three different sections were prepared, as illustrated in Fig. 7, 


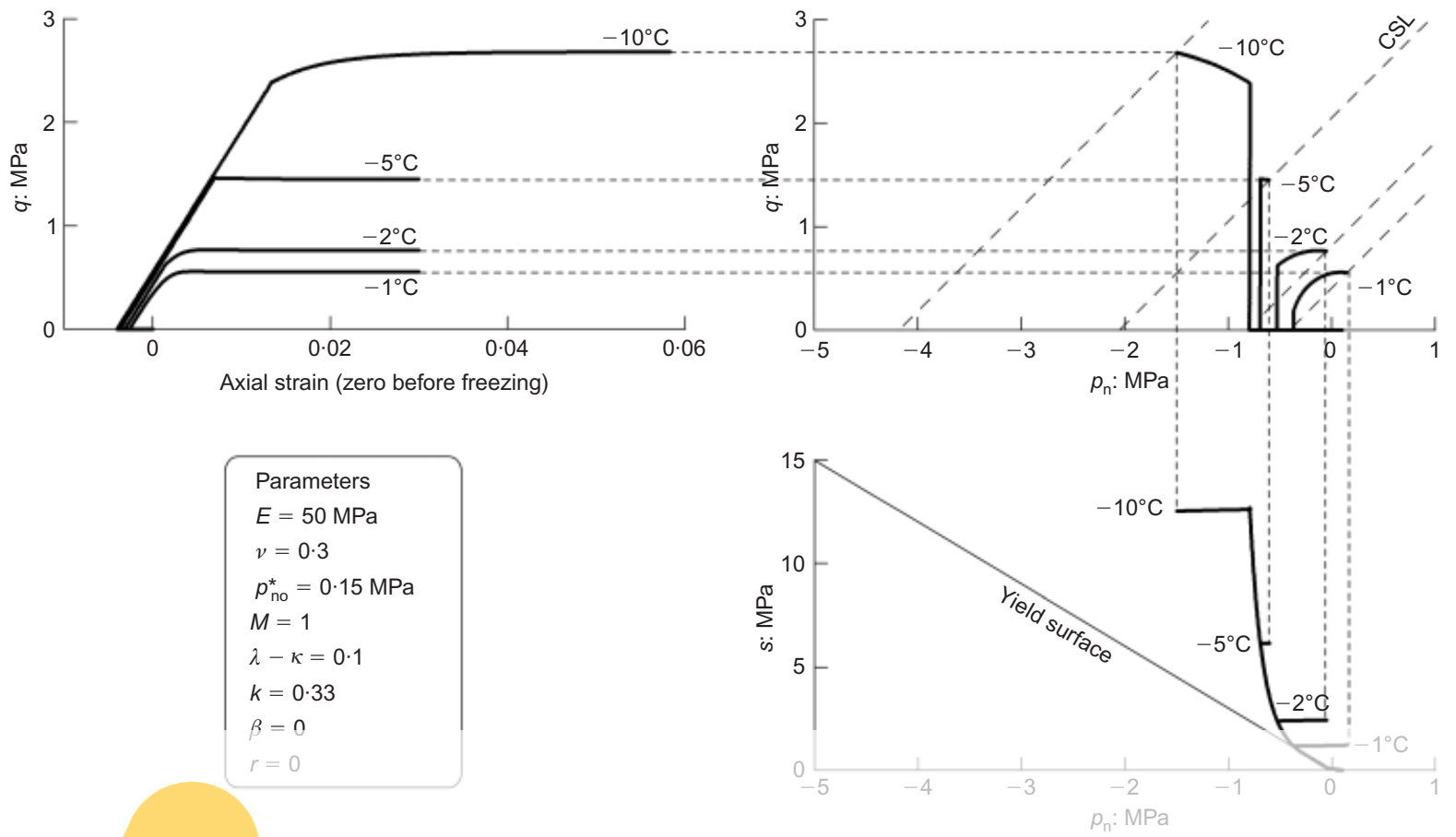

Fig. 5. Simulated behaviour during freezing to $-1{ }^{\circ} \mathrm{C},-2^{\circ} \mathrm{C},-5^{\circ} \mathrm{C}$ and $-10^{\circ} \mathrm{C}$ under isotropic stress and subsequent triaxial compression
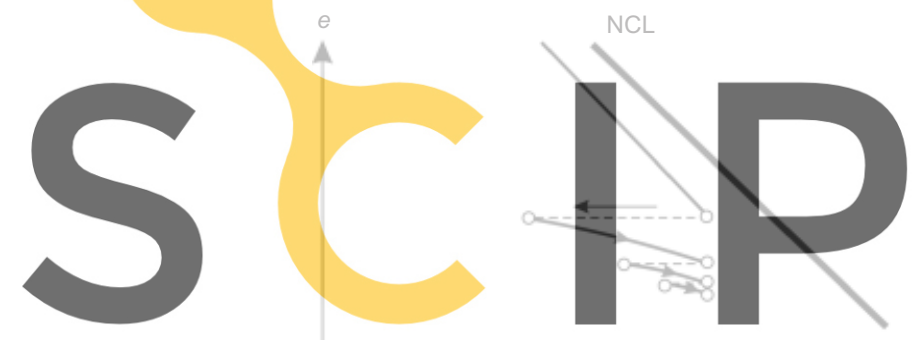

Freeze and

Register for free at https//wwW.scipedia.com to do (a)

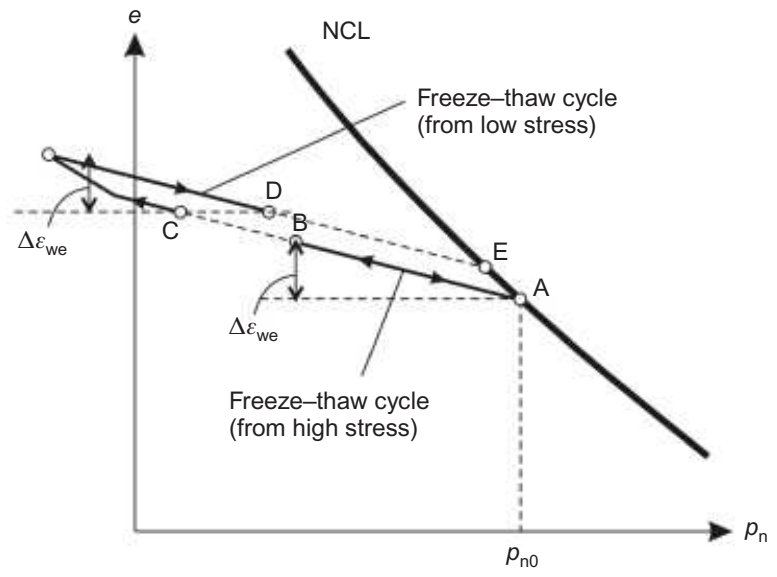

(b)

Fig. 6. Volume-stress relationships during undrained freeze and thaw, and subsequent consolidation under constant total stress: (a) experimentally observed under $K_{0}$ conditions (after Nixon \& Morgenstern, 1973); (b) the present model under isotropic conditions incorporating a berm that initially was $0.46 \mathrm{~m}$ high. The 'control' and 'gravel' sections had the pipeline invert set

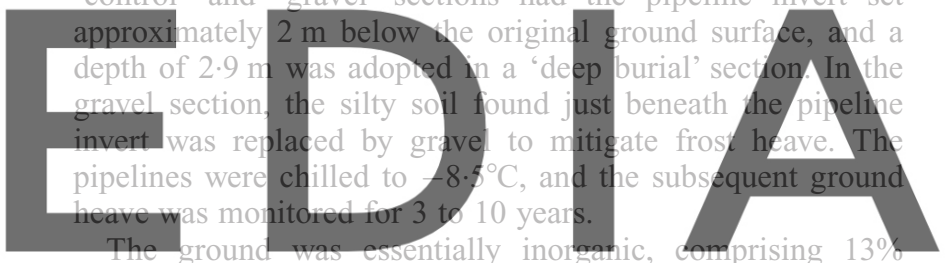

sand, $64 \%$ silt, and 23\% clay-sized particles. Its initial water content plastic limit and liquiditimit ranges were $18-22 \%$. indicated a relatively high mass permeability range of $0 \cdot 6-1$ $\times 10^{-6} \mathrm{~m} / \mathrm{s}$. However, the reported heavily fissured nature of the ground suggests that the micro- to mesoscopic permeability is likely to be significantly lower than this high mass value. The initial groundwater table was reported as being $2 \cdot 3-2.6 \mathrm{~m}$ below the original ground level.

Finite element meshes and boundary conditions

The spatial domain of the problem was discretised by designing a series of two-dimensional FE meshes, as shown in Fig. 8. The relatively narrow initial berms generated small surcharges $(<0.01 \mathrm{MPa})$, which were not modelled. However, their enlargement to $1.5 \mathrm{~m}$ height, performed 430 days after the start, was simulated by applying a ground level surcharge of $0.03 \mathrm{MPa}$ over $1.7 \mathrm{~m}$ to either side of the centreline.

The modelled domain was $15 \mathrm{~m} \times 15 \mathrm{~m}$ in extent. Relatively fine meshing was required to capture the active frozen fringe, where the permeability changed steeply with distance. Insufficiently fine meshes render the results inaccurate owing to interpolation errors in the degree of liquid saturation $S_{1}$, and hence of the hydraulic conductivity. Optimum meshing was determined in advance through onedimensional freezing analyses that considered the expected two-dimensional freezing rates and temperature gradients. It was concluded that elements should be no thicker than a third of the frozen fringe thickness. 


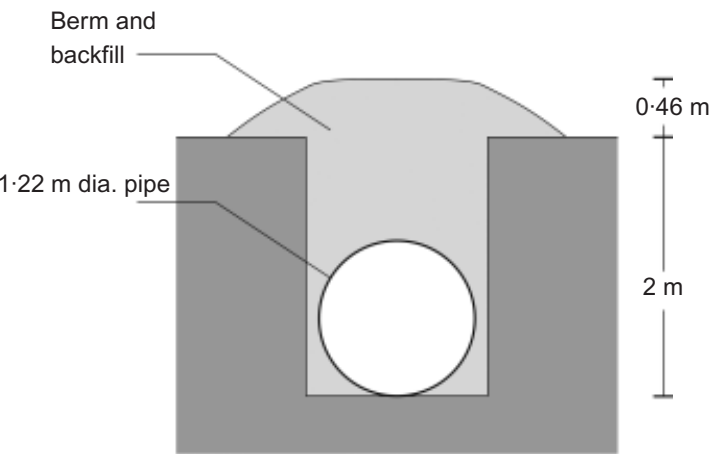

(a)

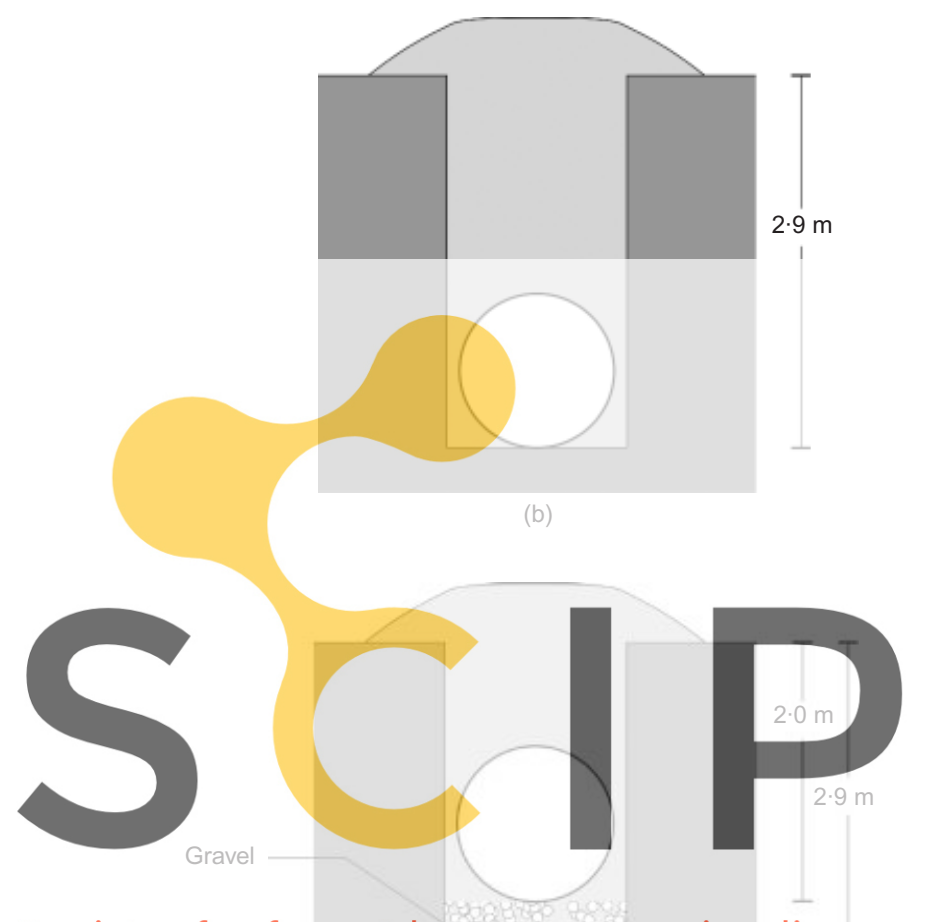

Register for free at https//www.scipedia.com to

It was assumed that the pipeline has negligible influence at $15 \mathrm{~m}$ from its axis, so zero heat flux/liquid flux conditions were specified along the lateral mesh boundaries. No heat flux was allowed along the bottom boundary, where the pore water pressure $P_{1}$ was specified to be $0.147 \mathrm{MPa}$, assuming hydrostatic conditions with groundwater to the surface. The hydraulic boundary conditions along the top boundary were set to give $P_{1}=0$ when $P_{1}$ was about to exceed 0 (i.e. free outgoing flow), but $\boldsymbol{q}_{1}=0$ was prescribed whenever $P_{l}$ became negative (i.e. no incoming flow). The surface thermal boundary conditions were prescribed as

$$
j^{\mathrm{e}}=\gamma_{\mathrm{e}}\left(T^{\mathrm{o}}-T\right)
$$

( $\boldsymbol{j}^{\mathrm{e}}$ is positive for inflow), where $\gamma_{\mathrm{e}}$ is a constant and $T^{\mathrm{o}}$ is the prescribed 'target' temperature. If $\gamma_{\mathrm{e}}$ is very large, $T^{\mathrm{o}}$ and $T$ have to be similar, but such a constraint becomes looser if $\gamma_{\mathrm{e}}$ is smaller. One way of interpreting the meaning of $\gamma_{\mathrm{e}}$ is to rewrite the above equation as

$$
j_{1}^{\mathrm{e}}=\lambda\left(\frac{T^{\mathrm{o}}-T}{L}\right)
$$

where $\gamma_{\mathrm{e}}$ is replaced by $\lambda / L$. Equation (23) can be thought of as representing a thin layer of non-soil surface insulation having a thickness $L$ and thermal conductivity $\lambda$. For example, $0.3 \mathrm{~m}$ of snow cover with a thermal conductivity of $0.3 \mathrm{~W} / \mathrm{m} \mathrm{K}$ could be represented by taking $\gamma_{\mathrm{e}}$ equal to $1 \mathrm{~W} /$ $\mathrm{m}^{2} \mathrm{~K}$. When snow is absent, the apparent ground surface insulation is controlled by more complex factors, including vegetation and evaporation characteristics. The present study

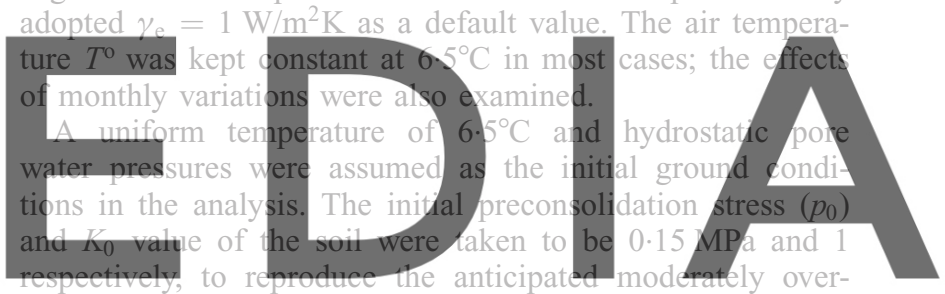

consolidated ground conditions. The pipeline temperature

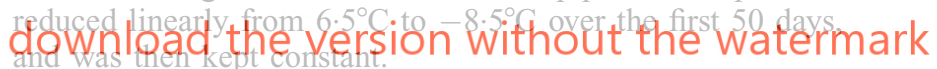

\section{Material parameters}

The material parameters selected for input are summarised in Table 1. The thermal properties of water may be considered as practically constant. The compressibility of ice was tentatively set to be the same as that of liquid water, an

Fig. 7. Sections constructed in in situ pipeline frost heave tests (after Slusarchuk et al., 1978): (a) control section; (b) deep burial section; (c) gravel section

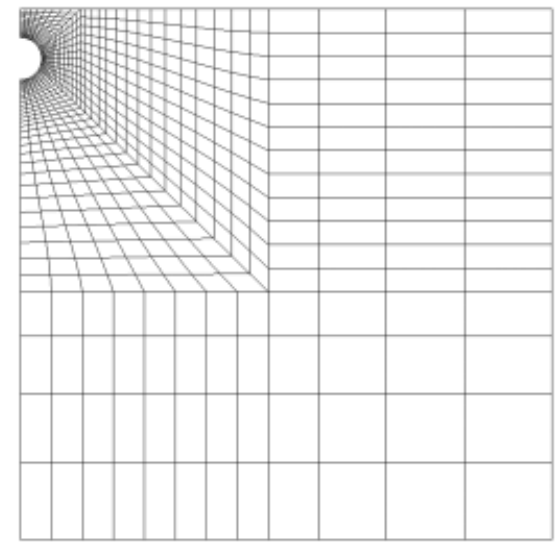

(a)

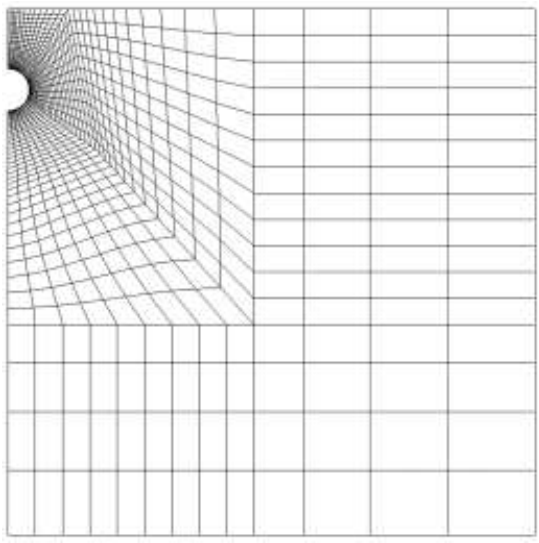

(b)

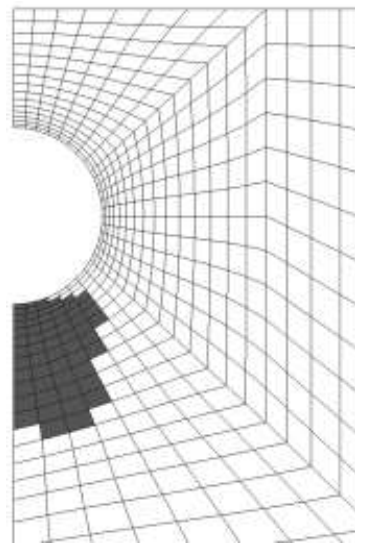

(c)

Fig. 8. Finite element meshes used in the analyses (pipeline elements are not shown, for clarity): (a) control section, 959 nodes; (b) deep burial section, 1346 nodes; (c) detail of gravel section (darker elements are assigned as gravel; otherwise same mesh as for the control section) 
Table 1. Standard silt properties input in the analysis

\begin{tabular}{l|c}
\hline Property & Value \\
\hline Thermal & \\
Thermal conductivity of soil particles, $\lambda_{s}: \mathrm{W} / \mathrm{m} \mathrm{K}$ & 3 \\
Thermal conductivity of liquid water, $\lambda_{1}: \mathrm{W} / \mathrm{m} \mathrm{K}$ & $2 \cdot 6$ \\
Thermal conductivity of ice, $\lambda_{\mathrm{i}}: \mathrm{W} / \mathrm{m} \mathrm{K}$ & 874 \\
Specific heat of soil particles, $c_{\mathrm{s}}: \mathrm{J} / \mathrm{kg} \mathrm{K}$ & 4190 \\
Specific heat of liquid water, $c_{1}: \mathrm{J} / \mathrm{kg} \mathrm{K}$ & 2095 \\
Specific heat of ice, $c_{\mathrm{i}}: \mathrm{J} / \mathrm{kg} \mathrm{K}$ & 334000 \\
Specific latent heat of fusion, $l: \mathrm{J} / \mathrm{kg}$ & \\
\hline Hydraulic & \\
Soil-water characteristic curve & $0 \cdot 17$ \\
$P:$ MPa & $0 \cdot 3$ \\
$\lambda$ & $0 \cdot 8 \times 10^{-15}$ \\
Intrinsic permeability, $k: \mathrm{m}^{2}$ &
\end{tabular}

(i.e. Unfrozen coefficient of permeability $=0.5 \times 10^{-8} \mathrm{~m} / \mathrm{s}$ )

Relative permeability, $\lambda$

assumption that is unlikely to affect the analysis significantly. The parameters for the soil-water characteristic curve, $\lambda$ and $P$, were obtained by fitting equation (6) to the freezing test data for the Calgary Silt given by Patterson \& Smith (1981). Although the parameters $\lambda$ in the soil-water characteristic curve (equation (5)) and in the relative permeability function (equation (10)) do not need to be identical, selecting $\lambda=0.3$ gave a reasonable match between the calculated relative permeability and the experimental data provided by Horiguchi \& Miller (1983) for the Calgary Silt.

The remaining input parameters had to be chosen to match those of a typical clayey silt. Adopting an assumed soil particle thermal conductivity of $\lambda_{\mathrm{s}}=3 \mathrm{~W} / \mathrm{m} \mathrm{K}$, equation (13) predicts overall soil thermal conductivities of $1.6 \mathrm{~W} /$ $\mathrm{mK}$ at $S_{1}=1$ and $2.6 \mathrm{~W} / \mathrm{m} \mathrm{K}$ at $S_{1}=0$. The value for the critical state parameter $M$ was set as 1 , which is equivalent to an angle of shearing resistance of $25^{\circ}$ in triaxial compression. The two-dimensional pipeline cross-section was modelled as an impervious disc of very stiff elastic material $(E=10000 \mathrm{MPa})$. The pipeline's surface temperatures were controlled as uniform boundary conditions, making its thermal properties irrelevant.

Bearing in mind the mesh size constraints described earlier, exact modelling of the gravel's hydraulic properties was difficult to achieve. This is because the gravel's frozen fringe is very thin in comparison with an affordable element size, owing to its very steep freezing characteristic function. The gravel parameters shown in Table 2 were selected to represent

(a) high unfrozen permeability $\left(K>10^{-3} \mathrm{~m} / \mathrm{s}\right.$, or $k>10^{-10} \mathrm{~m}^{2}$ )

(b) a freezing characteristic function similar to that of the silt

(c) a very rapid decrease in the relative permeability as $S_{1}$ decreases.

While $(a)$ and (c) represent the frost-resistant nature of

Table 2. Gravel hydraulic properties input in the analysis (the properties not shown were set to the same values as those shown in Table 1)

\begin{tabular}{l|c}
\hline Property & Value \\
\hline Soil-water characteristics curve & $0 \cdot 17$ \\
$P: \mathrm{MPa}$ & $0 \cdot 3$ \\
$\lambda$ & $1 \times 10^{-10}$ \\
Intrinsic permeability, $k: \mathrm{m}^{2}$ & (i.e. Unfrozen coefficient of \\
& permeability $=6 \times 10^{-4} \mathrm{~m} / \mathrm{s}$ ) \\
at $T=0^{\circ} \mathrm{C}$ \\
$0 \cdot 01$ \\
Relative permeability, $\lambda$ & 0. \\
\hline
\end{tabular}


gravel, $(b)$ represents a less realistic compromise, adopted to render the computation feasible without recourse to extremely small elements. This modelling may lead to a thicker computed gravel frozen fringe than would actually develop. However, characteristic (c) ensures no significant increase of liquid flux while keeping the gravel non-susceptible to frost heaving.

\section{Simulated segregation potential}

The segregation potential theory proposed by Konrad \& Morgenstern $(1980,1981)$ has been widely applied in frost heave analysis, including successful simulations of the Calgary pipeline trials by Konrad \& Morgenstern (1984). Their study allows useful comparisons with the proposed THM approach. The segregation potential, SP, is defined as a coefficient relating the liquid flux into the frozen fringe and temperature gradient across it:

$$
q_{1}=\mathrm{SP} \frac{\partial T}{\partial x}
$$

$\mathrm{SP}$ varies with many factors. However, considering cases involving slow field cooling rates, Konrad \& Morgenstern $(1982,1984)$ simplified the function to

$$
\mathrm{SP}=\mathrm{SP}_{0} \exp \left(-a P_{\mathrm{e}}\right)
$$

where $\mathrm{SP}_{0}$ and $a$ are considered constant (with $2.3 \times$ $10^{-9} \mathrm{~m} / \mathrm{s} \mathrm{K}$ and $9 \cdot 5$, respectively, being selected by Konrad \& Morgenstern, 1984, for the Calgary case), and $P_{\mathrm{e}}$ is the overburden pressure. A series of one-dimensional freezing simulations was performed by the authors that emulated a centroline vertical column in the control section. The oomputer liquid flux and the liquid frem the segregation potential the interesting to note that the THM order of liquid flux as the the assumed intrinsic segation abilities being 100 , or more, times lower than the reported in situ bulk value. Since Register for tree ât derived from laboratopy uniaxial freezfield measurement may have overestimated the micro- to mesoscale local permeability relevant to the frost heave problem.

\section{Simulated frost heave of pipeline}

The simulated pipeline heave developments are compared with the field measurements in Fig. 10. The intrinsic permeability value was set as $0.8 \times 10^{-15} \mathrm{~m}^{2}$ in all the simulations shown. The time history of the heave in the deep

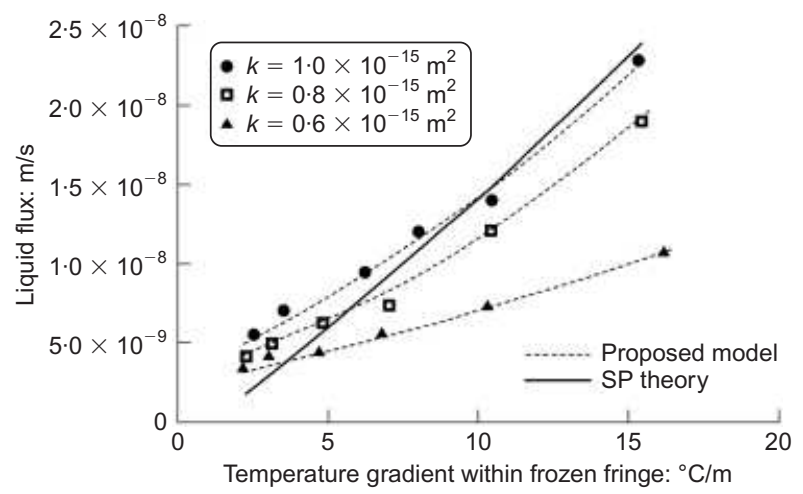

Fig. 9. Comparison of one-dimensional liquid flux: temperature gradient relationships simulated by the proposed model and the segregation potential theory

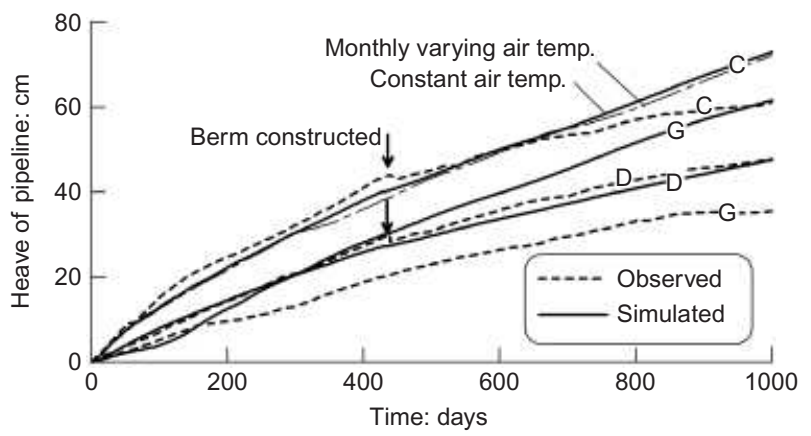

Fig. 10. Simulated and observed heave of pipeline: $C$, control section; D, deep burial section; G, gravel section

burial section is well predicted over three years. The control section prediction is also good up to the berm enlargement at day 430. From this point onwards, however, the simulated heave rates exceed the measurements. One plausible explanation is the site non-uniformity noted by Slusarchuk et al. (1978). In particular, the deeper ground may have been less frost heave-susceptible than the shallow material against which the model was calibrated. Other possible factors are that: (a) the assumed soil stiffness may have been excessive, leading to an underestimate of the instantaneous settlement at day 430, and of the subsequent consolidation settlement; and (b) determination of the hydraulic parameters based on large temperature gradient conditions may have led to overprediction of liquid flux at stages where the temperature

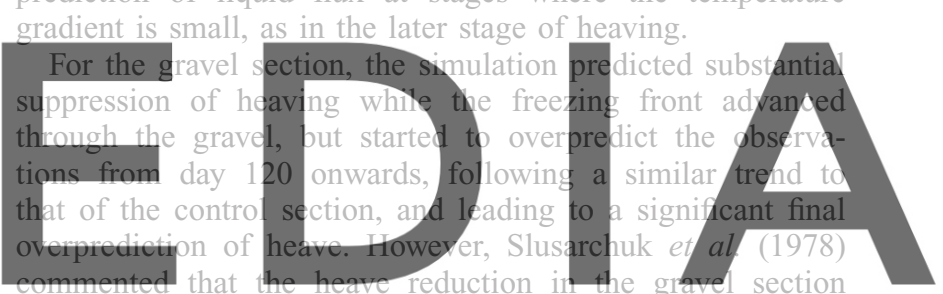

was probably due to lateral geotechnical variations and the

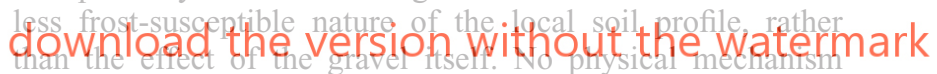
has been postulated to explain how gravel could continue to influence the heave rate once it has become completely contained within the frozen domain.

The influence of the intrinsic permeability was evaluated in the control section by inputting alternative values of $k=$ $0.6 \times 10^{-15}$ and $1.0 \times 10^{-15} \mathrm{~m}^{2}$. The simulated pipeline heaves are shown in Fig. 11. The heave rate appears approximately proportional to the (intrinsic) permeability-a logical consequence of employing Darcy's law.

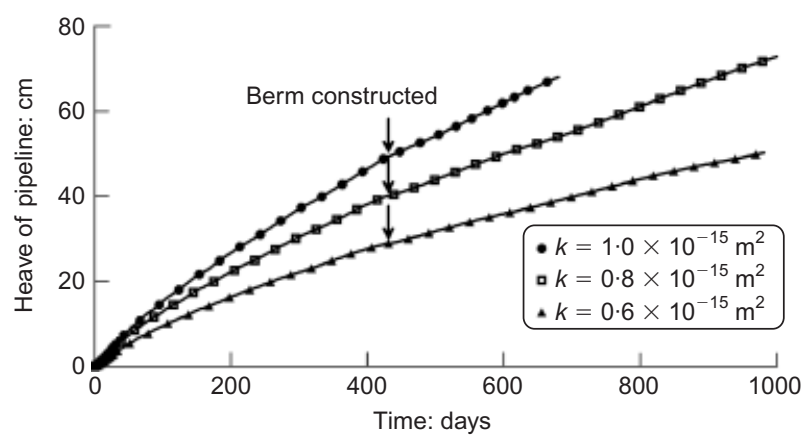

Fig. 11. Influence of permeability on simulated heave of pipeline in control section 
Influence of ground surface thermal boundary conditions

The deformed meshes for the control section are shown in Figs 12(a) and 12(b) for days 300 and 1000. The excessive deformation of finite elements seen at the heave-shoulder location in Fig. 12(b) derives from the steep local temperature gradient caused by pipeline cooling, and the specified positive ground surface temperature. Such deformation may be curbed in the field by intermittent cavitation and desiccation in the near-surface ground, and hence disruption of water flow. These factors were not modelled in the simulations. Another relevant factor is the impedance of near-surface water flow by surface ground freezing during winter. In order to consider the latter, additional simulations were made for the control section, in which the air temperature ( $T^{\circ}$ in equation (22)) was varied on a monthly basis, between $-8^{\circ} \mathrm{C}$ in January and $+16 \cdot 5^{\circ} \mathrm{C}$ in July. The mesh deformation for day 1000 , shown in Figs 12(c) and 12(d), indicates more realistic heave patterns. Note that the undulation in the heaved ground surface is caused by seasonal freezing, with the first centreline 'bump' developing during the first summer, and the second at the shoulder in the second summer.

The pipeline heaves predicted by analyses run with both constant and monthly varying temperature inputs are compared in Fig. 10. Unlike the surface heave, the pipeline displacements do not appear to be significantly affected by the surface temperature conditions, because the annual temperature variations fall with depth, and are greatly reduced at the pipeline invert level (Nishimura et al., 2009). The temperature contours computed for four different months are shown in Fig. 13. Whereas the temperatures around and below the pipeline show little seasonal variation, the ground

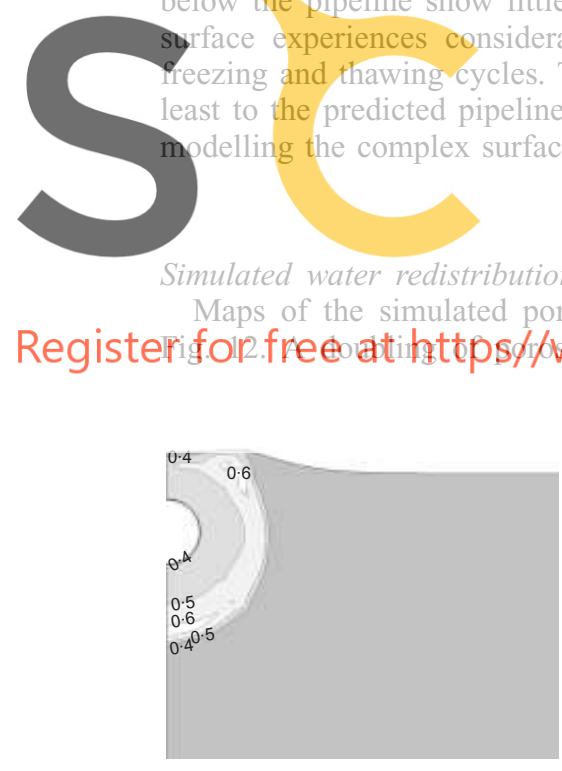

(a)

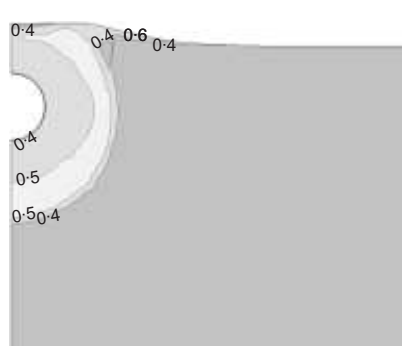

(c)

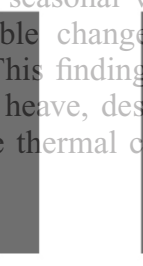

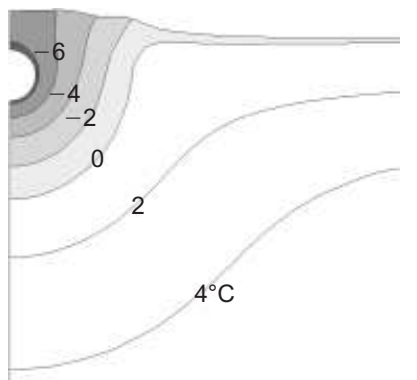

(a)

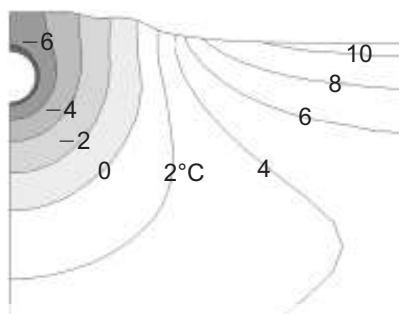

(c)

Fig. 13. Temperature contours computed with monthly varying air temperature: (a) day 772 (February); (b) day 863 (May); (c) day 954 (August); (d) day 1046 (December)

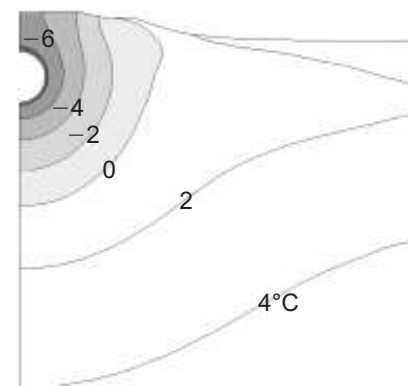

(b)

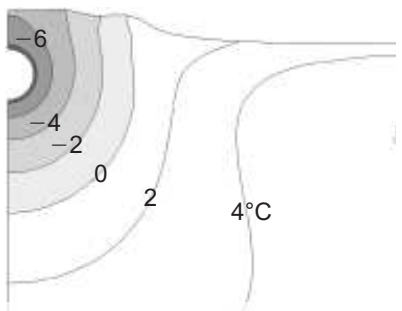

(d)

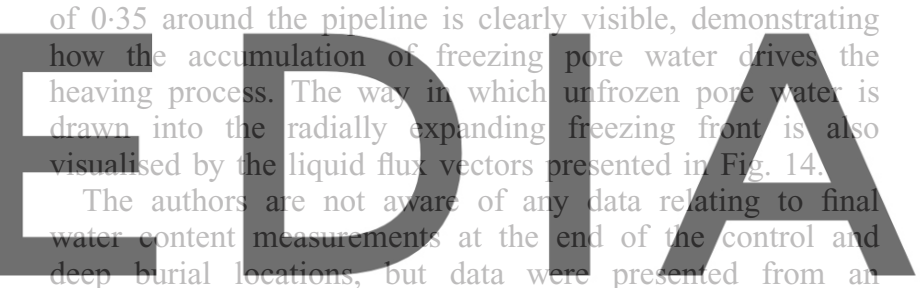

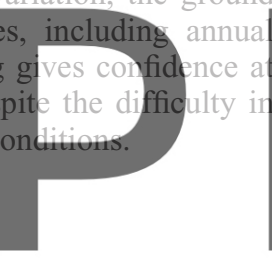

ges are presented in additional 'insulated silt' section by Carlson \& Nixon

carlson \& Nixon

ownload the version without the watermark

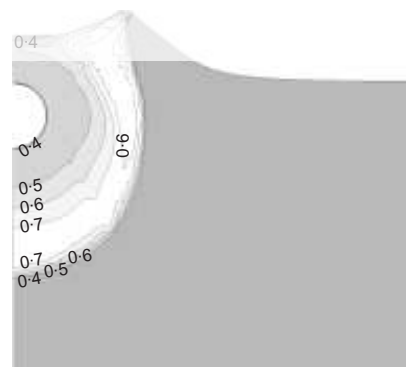

(b)

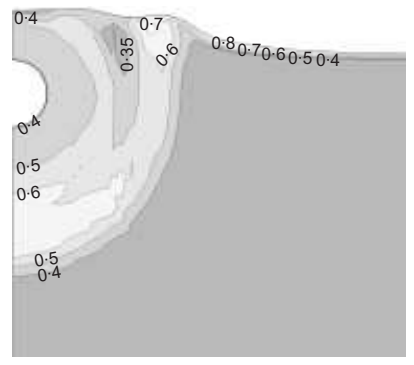

(d)

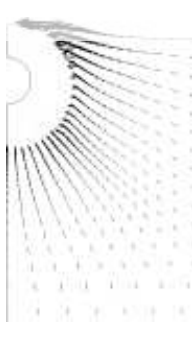

(a)

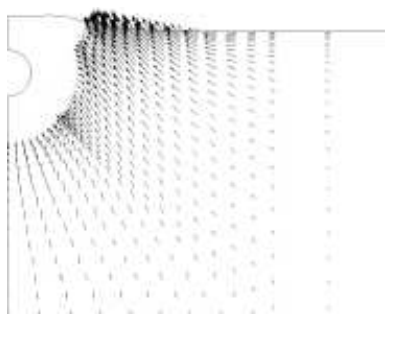

(c)

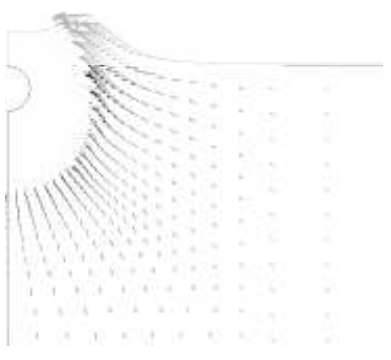

(b)

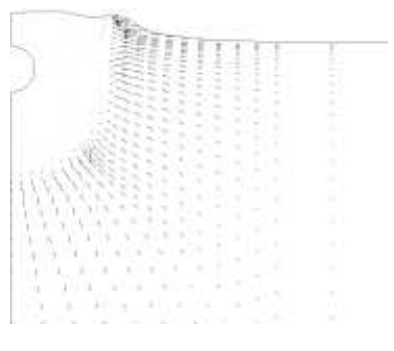

(d)

Fig. 12. Deformed geometry and porosity contours predicted for control section at (a) day 300 and (b) day 1000 for constant air temperature, and (c) day 300 and (d) day 1000 for monthly varying air temperature

Fig. 14. Vectors showing flux of pore water towards freezing front, predicted for control section at (a) day 300 and (b) day 1000 for constant air temperature, and (c) day 300 and (d) day 1000 for monthly varying air temperature 
with an additional insulation layer placed around the pipe. The measured water content profile at the pipe centreline is shown in Fig. 15, along with the simulated water contents for the control and deep burial sections. The frost penetration depths were not significantly different in the two simulated cases at day 1000 , and the observed depth was well predicted. The observed insulated silt water content profile was closer to that predicted for the deep burial section than for the control section. The insulation around the pipe may have curbed the frost heave in a way comparable to the deep burial. The THM simulation reproduces the field trend for water content to increase gradually from the pipeline invert down to the freezing front

Heave resistance by overlying soil

Another important positive feature of THM modelling is its ability to predict the stress and strain states developed in the soil, and their variations, during freezing and thawing. Fig. 16 illustrates this aspect by indicating how the shear stress $\tau_{x y}$ (the $y$-axis is defined as the vertical) develops as freezing progresses in the control and deep burial section cases. The initial development of negative shear stresses at the pipeline shoulder, which act downwards to resist the upheaval of the pipeline and the frozen soil around it, can be seen in Fig. 16. It may therefore be argued that the suppressed heave in the deep burial section derives from the larger shear force exerted by soil away from the centreline, in addition to the larger weight of the overlying soil. As the resisting soil at the pipeline shoulder is engulfed within the frozen zone, however, the stress state at this location becomes irrelevant to the heaving, and the frozen zone moves upwards with an almost rigid block mechanism.

The ultimate uplift resistance offered by the soil overlying the pipeline was considered by Carlson \& Nixon through a simplified limit equilibrium approach by assuming (a) a planar failure mechanism, (b) a critical orientation for the plane, and (c) an operational angle of soil shearing resistance. In the proposed THM-coupled continuum approach, however, the failure mechanism, operational shear strengths

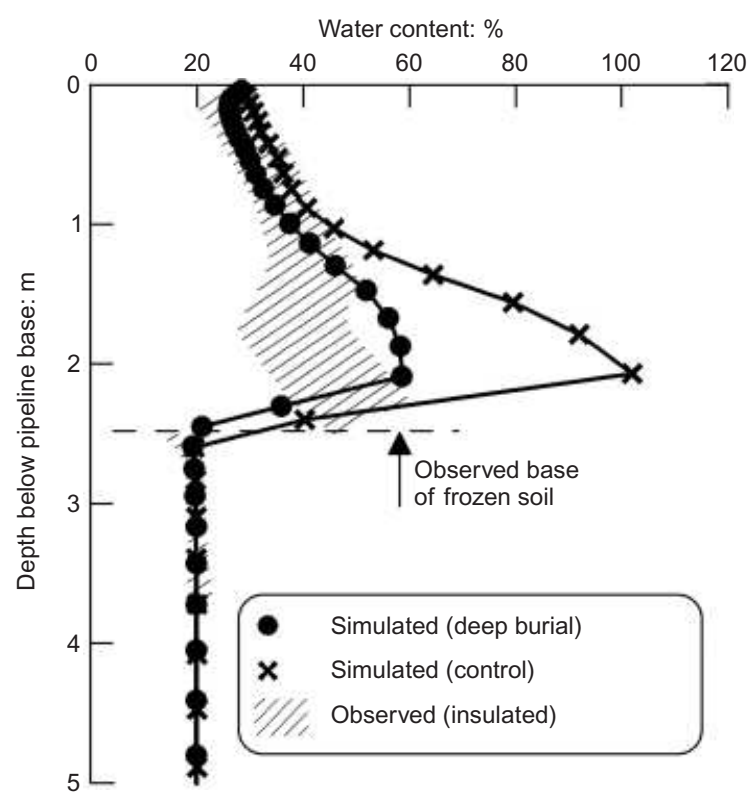

Fig. 15. Simulated and observed water content profiles beneath pipeline. Note that the measurement was conducted for the 'insulated silt' section

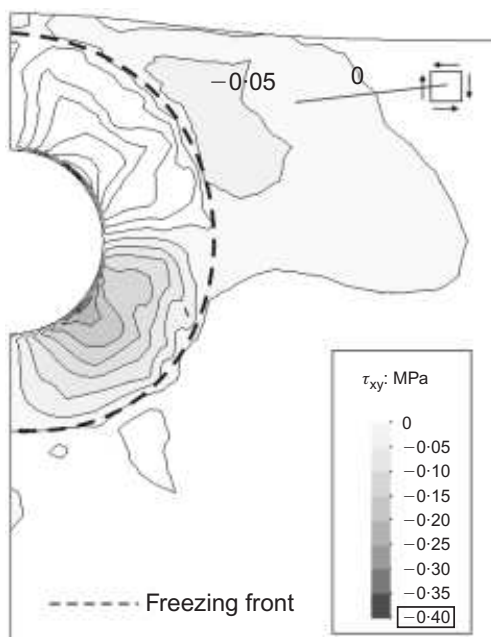

(a)

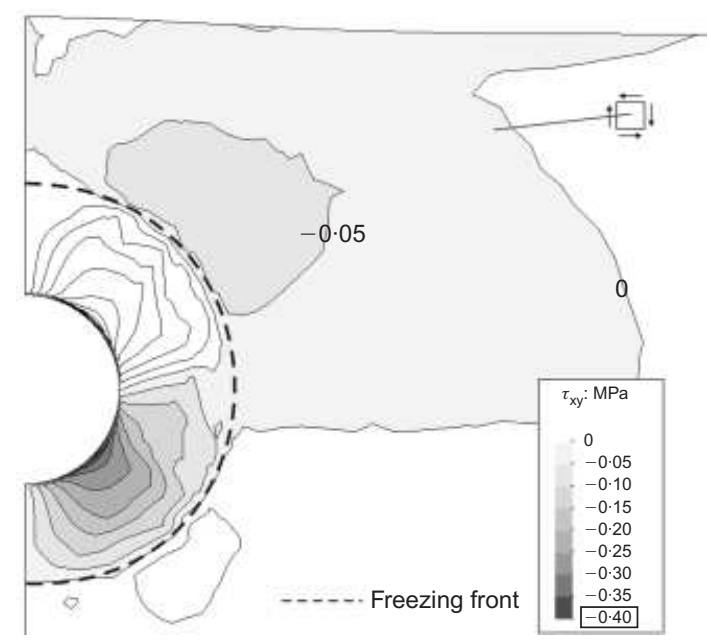

(b)

Fig. 16. Shear stresses $\tau_{x y}$ developed inside and outside the frost zone at day 60: (a) control section; (b) deep burial section

and ground deformation all emerge spontaneously as model outputs.

\section{CONCLUSIONS}

A fully coupled THM model has been developed to consider a variety of geological and geotechnical processes involving freezing and thawing soils. The governing equations were developed from fundamental physical requirements. By solving the coupled equations, the interactions between frozen soils' thermal, hydraulic and mechanical processes can be simulated. New developments include a new critical state elasto-plastic mechanical constitutive model that adopts total stress, liquid pressure and ice pressure. The constitutive model reduces to an effective stress-based model similar to the Modified Cam-Clay model under unfrozen conditions. Many essential features of frozen soils' mechanical behaviour, including the dependence of shear strength on temperature and porosity, are captured, but modelling of additional time-dependent or cyclic features requires further development. The proposed framework allows existing unfrozen soil model developments, such as overstress viscoplasticity and multiple-surface plasticity, to be applied readily in potential future elaborations.

The performance of the proposed formulation was tested by considering the important cold region infrastructure topic 
of frost heaving. Experiments conducted with buried large chilled gas pipelines by Slusarchuk et al. (1978) were simulated, considering three different test conditions. Some important questions regarding numerical implementation have been addressed, including appropriate FE mesh design, selection of hydraulic parameter values, and setting of realistic boundary conditions at the air/ground interface. Of particular importance was the determination of permeability. The range of permeability values, which reproduced both Konrad \& Morgenstern's (1984) segregation potential parameters (obtained from laboratory tests) and the frost heave observed in situ, fell two orders of magnitude below a bulk value reported from in situ testing. Frost heave is governed by processes that develop within relatively thin frozen fringes; scale effects may be important, and bulk permeability values measured at a large scale may not be representative in fissured, heterogeneous, ground.

Critical examination of the analytical predictions and the field test data confirms that the new THM model can simulate, with fair accuracy, the field patterns of pipeline heave, water migration and ice accumulation. The experimentally proven alleviation of heave by deeper burial was modelled successfully. The increased shear resistance developed in unfrozen soil above the pipeline was found to contribute to the reduction of heave.

\section{ACKNOWLEDGEMENTS}

The work described formed part of an Imperial College project funded by BP that aimed to investigate the possible impacts of climate change on cold region infrastructure. The authors thank their sponsors for permission to publish the results. They also acknowledge the contributions made to the project by Mr Jim Clarke from BP and colleagues at Imperial College: Dr Clark Fenton and Mr Chris Martin.

\section{NOTATION}

a parameter in segregation potential function

$\boldsymbol{b}$ body force vector

$c_{\mathrm{S}}, c_{1}, c_{\mathrm{i}}$ specific heats of soil particle, liquid water and ice $e$ void ratio

$e_{\mathrm{s}}, e_{1}, e_{\mathrm{i}}$ specific internal energies of soil particle, liquid water and ice

E Young's modulus

$f^{\mathrm{e}}$ sink/production term of energy

$f^{\mathrm{w}}$ sink/source term of mass

$g$ gravity acceleration vector

$j_{1}^{\mathrm{e}}$ advective term of heat flux

$[K], K$ hydraulic conductivity (matrix), bulk modulus

$[k], k$ intrinsic permeability (matrix), constitutive model parameter

$k_{\mathrm{r}} \quad$ liquid relative permeability

$l$ specific latent heat of fusion

$M$ constitutive model parameter

$P$ freezing characteristic function parameter

$P_{\mathrm{b}}, P_{\mathrm{i}} \quad$ liquid water and ice pressure

$P_{\mathrm{e}} \quad$ overburden pressure in segregation potential theory

$p$ mean stress

$p^{\prime}$ mean effective stress

$p^{\mathrm{c}}$ constitutive model parameter

$p_{\mathrm{n}} \quad$ stress variable

$p_{\mathrm{n} 0}, p_{\mathrm{n} 0}^{*}$ constitutive model parameter

$q$ deviatoric stress

$q_{1}$ liquid water flux

$r$ constitutive model parameter

$S_{1}, S_{\mathrm{i}}$ degree of liquid water saturation and ice saturation

$s$ stress variable

$s_{1}, s_{\mathrm{i}}$ specific entropies of liquid water and ice

SP segregation potential

$T$ temperature

$T_{\mathrm{f}}$ freezing temperature $v_{\mathrm{l}}, v_{\mathrm{i}}$ specific volumes of liquid water and ice

$w_{\mathrm{u}}$ unfrozen water content

$\beta$ constitutive model parameter

$\gamma_{\mathrm{e}}$ coefficient controlling boundary conditions

$\delta_{i j} \quad$ Kronecker delta

$\boldsymbol{\varepsilon}$ strain

$\varepsilon_{\mathrm{v}}^{\mathrm{p}} \quad$ volumetric plastic strain

$\kappa$ constitutive model parameter

$\lambda$ freezing characteristic function parameter, liquid relative permeability function parameter, overall thermal conductivity of soil, parameter in constitutive model

$\lambda(0)$ constitutive model parameter

$\lambda_{\mathrm{s}}, \lambda_{\mathrm{l}}, \lambda_{\mathrm{i}}$ thermal conductivities of soil particle, liquid water and ice

$\mu_{1} \quad$ liquid viscosity

$\rho_{\mathrm{s}}, \rho_{\mathrm{l}}, \rho_{\mathrm{i}}$ mass densities of soil particle, liquid water and ice

$\boldsymbol{\sigma}, \sigma_{i j} \quad$ stress

$\boldsymbol{\sigma}_{\mathrm{b}}$ Bishop stress

$\phi$ porosity

$\chi$ Bishop stress factor

\section{REFERENCES}

Alonso, E. E., Gens, A. \& Josa, A. (1990). A constitutive model for partially saturated soils. Géotechnique 40, No. 3, 405-430.

Andersland, O. B. \& Ladanyi, B. (2004). Frozen ground engineering, 2nd edn. Hoboken, NJ: John Wiley \& Sons.

Anderson, D. M. \& Morgenstern, N. R. (1973). Physics, chemistry and mechanics of frozen ground: a review. Proc. 2nd Int. Conf. on Permafrost, Yakutsk; North American contribution, Washington DC, 257-288.

Arenson, L. U. \& Springman, S. M. (2005). Mathematical descriptions for the behaviour of ice-rich frozen soils at temperature close to $0^{\circ} \mathrm{C}$. Can. Geotech. J. 42, No. 2, 431-442.

Bishop, A. W. \& Blight, G. E. (1963). Some aspects of effective stress in saturated and partly saturated soils. Géotechnique 13, No. 3, 177-197.

Black, P. B. \& Tice, A. R. (1989). Comparison of soil freezing curve and soil water curve data for Windsor Sandy Loam. Water Resour. Res. 25, No. 10, 2205-2210.

Blanchard, D. \& Fremond, M. (1985). Soils frost heaving and thaw settlement. Proc. 4th Int. Symp. on Ground Freezing, Sapporo 1, 209-216.

Bragg, R. A. \& Andersland, O. B. (1981). Strain rate, temperature, and sample size effects on compression and tensile properties of frozen sand. Engng Geol. 18, 35-46.

Carlson, L. E. \& Nixon, J. F. (1988). Subsoil investigation of ice lensing at the Calgary, Canada, frost heave test facility. Can. Geotech. J. 25, No. 2, 307-319.

Clarke, J., Fenton, C., Gens, A., Jardine, R., Martin, C., Nethercot, D., Nishimura, S., Olivella, S., Reifen, C., Rutter, P., Strasser, F. \& Toumi, R. (2008). A multi-disciplinary approach to assess the impact of global climate change on infrastructure in cold regions. Proc. 9th Int. Conf. on Permafrost, Fairbanks, 279-284.

Côté, J. \& Konrad, J.-M. (2005). A generalized thermal conductivity model for soils and construction materials. Can. Geotech. J. 42, No. 2, 443-458

Coussy, O. (2005). Poromechanics of freezing materials. J. Mech. Phys. Solids 53, No. 8, 1689-1718.

Fredlund, D. G. (2000). The implementation of unsaturated soil mechanics into geotechnical engineering: R. M. Hardy Lecture. Can. Geotech. J. 37, 963-986.

Fredlund, D. G. \& Morgenstern, N. R. (1976). Constitutive relations for volume change in unsaturated soils. Can. Geotech. J. 13, No. 5, 261-276.

Fredlund, D. G. \& Xing, A. (1994). Equations for the soil-water characteristic curve. Can. Geotech. J. 31, No. 4, 521-532.

Gens, A. (2007). Soil-environment interactions in geotechnical engineering: 47th Rankine Lecture. Géotechnique (in preparation).

Gens, A., Garcia-Molina, A. J., Olivella, S., Alonso, E. E. \& Huertas, F. (1998). Analysis of a full scale in situ test simulating repository conditions. Int. J. Numer. Anal. Methods Geomech. 22, No. 7, 515-548.

Gens, A., Sanchez, M. \& Sheng, D. (2006). On constitutive modelling of unsaturated soils. Acta Geotech. 1, No. 3, 137-147. 
Gilpin, R. R. (1980). A model for the prediction of ice lensing and frost heave in soils. Water Resour. Res. 16, No. 5, 918-930.

Goughnour, R. R. \& Andersland, O. B. (1968). Mechanical properties of a sand-ice system. J. Soil Mech. Found. Div. ASCE 94, No. SM4, 923-950.

Grant, S. A. \& Sletten, R. S. (2002). Calculating capillary pressures in frozen and ice-free soils below the melting temperature. Environ. Geol. 42, No. 2-3, 130-136.

Guymon, G. L. \& Luthin, J. N. (1974). A coupled heat and moisture transport model for arctic soils. Water Resour. Res. 10, No. 5, 995-1001.

Hansson, K. \& Lundin, L.-C. (2006). Equifinality and sensitivity in freezing and thawing simulations of laboratory and in situ data. Cold Regions Sci. Technol. 44, No. 1, 20-37.

Hansson, K., Simunek, J., Mizoguchi, M., Lundin, L.-C. \& van Genuchten, M. Th. (2004). Water flow and heat transport in frozen soil: numerical solution and freeze-thaw applications. Vadose Zone 3, 693-704.

Harlan, R. L. (1973). Analysis of coupled heat-fluid transport in frozen soil. Water Resour. Res. 9, No. 5, 1314-1323.

He, P., Zhu, Y., Xian, C. \& Xhang, Z. (1997). Constitutive relation of saturated frozen silt in torsion. Proceedings of the international symposium on ground freezing and frost action in soils, Lulea, pp. 313-316.

He, P., Zhu, Y. \& Cheng, G. (2000). Constitutive models of frozen soil. Can. Geotech. J. 37, No. 4, 811-816.

Henry, K. S. (2000). A review of the thermodynamics of frost heave, Technical Report ERDC/CRREL TR-00-16. US Army Corps of Engineers.

Horiguchi, K. \& Miller, R. D. (1983). Hydraulic conductivity functions of frozen materials. Proc. 4th Int. Conf. on Permafrost, Fairbanks, 504-508.

Jame, Y. W. \& Norum, D. I. (1980). Heat and mass transfer in freezing unsaturated porous medium. Water Resour. Res. 16, No. 4, 811-819.

Jessberger, H. L. (1981). A state-of-the-art report. Ground freezing: mechanical properties, processes and design. Engng Geol. 18, $5-30$.

Konrad, J.-M. \& Morgenstern, J. R. (1980). A mechanistic theory of ice lens formation in fine-grained soils. Can. Geotech. J. 17, No. 4, 473-486.

Konrad, J.-M. \& Morgenstern, J. R. (1981). The segregation potential of a freezing soil. Can. Geotech. J. 17, 482-491.

Konrad, J.-M. \& Morgenstern, J. R. (1982). Effects of applied pressure on freezing soils. Can. Geotech. J. 19, No. 4, 494-505.

Konrad, J.-M. \& Morgenstern, J. R. (1984). Frost heave prediction of chilled pipelines buried in unfrozen soils. Can. Geotech. J. 21, No. 1, 100-115.

Koopmans, R. W. R. \& Miller, R. D. (1966). Soil freezing and soil water characteristics curves. Soil Sci. Soc. Am. J. 30, No. 6, $680-685$.

Kujala, K. (1997). Estimation of frost heave and thaw weakening by statistical analyses. Proceedings of the international symposium on ground freezing and frost action in soils, Lulea, pp. $31-41$

Ladanyi, B. (1972). An engineering theory of creep of frozen soils. Can. Geotech. J. 9, No. 1, 63-80.

Ladanyi, B. (1975). Bearing capacity of strip footings in frozen soils. Can. Geotech. J. 12, No. 3, 393-407.

Ladanyi, B. \& Johnston, G. H. (1974). Behavior of circular footings and plate anchors embedded in permafrost. Can. Geotech. J. 11, No. 4, 531-553.

Ladanyi, B. \& Morel, J.-F. (1990). Effect of internal confinement on compression strength of frozen sand. Can. Geotech. J. 27, No. $1,8-18$.

Li, N., Chen, B., Chen, F. \& Xu, X. (2000). The coupled heatmoisture-mechanic model of the frozen soil. Cold Regions Sci. Technol. 31, No. 3, 199-205.

Li, N., Chen, F., Su, B. \& Cheng, G. (2002). Theoretical frame of the saturated freezing soil. Cold Regions Sci. Technol. 35, No. 2, 73-80.

Miller, R. D. (1978). Frost heaving in non-colloidal soils. Proc. 3rd Int. Conf. on Permafrost, Edmonton, 708-713.
Nakano, Y. (1997). A mathematical model called $\mathrm{M}_{1}$ and the Gilpin model of soil freezing. Proceedings of the international symposium on ground freezing and frost action in soils, Lulea, pp. 139-146.

Newman, G. P. \& Wilson, G. W. (1997). Heat and mass transfer in unsaturated soils during freezing. Can. Geotech. J. 34, No. 1, 63-70.

Nishimura, S., Martin, C. J., Jardine, R. J. \& Fenton, C. H. (2009). A new approach for assessing geothermal response to climate change in permafrost regions. Géotechnique 59, No. 3, 213-227.

Nixon, J. F. (1978). Foundation design approaches in permafrost areas. Can. Geotech. J. 15, No. 1, 96-112.

Nixon, J. F. (1990). Effect of climate warming on pile creep in permafrost. J. Cold Regions Engng ASCE 4, No. 1, 67-73.

Nixon, J. F. (1991). Discrete ice lens theory for frost heave in soils. Can. Geotech. J. 28, No. 6, 843-859.

Nixon, J. F. \& Morgenstern, N. R. (1973). The residual stress in thawing soils. Can. Geotech. J. 10, No. 4, 571-580.

Olivella, S., Carrera, J., Gens, A. \& Alonso, E. E. (1994). Nonisothermal multiphase flow of brine and gas through saline media. Transp. Porous Media 15, No. 3, 271-293.

Olivella, S., Gens, A., Carrera, J. \& Alonso, E. E. (1996). Numerical formulation for a simulator 'CODE_BRIGHT' for the coupled analysis of saline media. Engng Comput. 13, No. 7 , $87-112$.

O’Neill, K. \& Miller, R. D. (1985). Exploration of a rigid ice model of frost heave. Water Resour. Res. 21, No. 3, 281-296.

Ouvry, J. F. (1985). Results of triaxial compression tests and triaxial creep tests on an artificially frozen stiff clay. Proc. 4th Int. Symp. on Ground Freezing, Sapporo 2, 207-212.

Parameswaran, V. R. (1980). Deformation behaviour and strength of frozen sand. Can. Geotech. J. 17, No. 1, 74-88.

Patterson, D. E. \& Smith, M. W. (1981). The measurement of unfrozen water content by time-domain reflectometry: results from laboratory tests. Can. Geotech. J. 18, No. 1, 131-144.

Romanovsky, V. E. \& Osterkamp, T. E. (2000). Effect of unfrozen water on heat and mass transport processes in the active layer and permafrost. Permafrost and Periglacial Processes 11, No. 3, 219-239.

Roscoe, K. H. \& Burland, J. B. (1968). On the generalised stressstrain behaviour of 'wet' clay. In Engineering plasticity (eds J. Heyman and F. A. Leckie), pp. 535-609. Cambridge: Cambridge University Press.

Sayles, F. H. (1988). State of the art: mechanical properties of frozen soil. Proc. 5th Int. Symp. on Ground Freezing, Nottingham, 143-165.

Selvadurai, A. P. S., Hu, J. \& Konuk, I. (1999a). Computational modelling of frost heave induced soil-pipeline interaction I. Modelling of frost heave. Cold Regions Sci. Technol. 29, No. 3, $215-228$.

Selvadurai, A. P. S., Hu, J. \& Konuk, I. (1999b). Computational modelling of frost heave induced soil-pipeline interaction II. Modelling of experiments at the Caen test facility. Cold Regions Sci. Technol. 29, No. 3, 229-257.

Shibata, T., Adachi, T., Yashima, A., Takahashi, T. and Yoshioka, I. (1985). Time-dependent and volumetric change characteristics of frozen sand under triaxial stress conditions. Proceedings of the 4th International Symposium on Ground Freezing, Sapporo, 1, $173-179$

Slusarchuk, W. A., Clark, J. I., Nixon, J. F., Morgenstern, N. R. \& Gaskin, P. N. (1978). Field test results of a chilled pipeline buried in unfrozen ground. Proc. 3rd Int. Conf. on Permafrost, Edmonton 1, 878-883.

van Genuchten, M. Th. (1980). A closed-form equation for predicting the hydraulic conductivity of unsaturated soils. Soil Sci. Soc. Am. J. 44, 892-898.

Wang, D., Ma, W. \& Chang, X. (2004). Analyses of behavior of stress-strain of frozen Lanzhou loess subjected to K0 consolidation. Cold Regions Sci. Technol. 40, Nos 1-2, 19-29.

Williams, P. J. (1964). Unfrozen water content of frozen soils and soil moisture suction. Géotechnique 14, No. 3, 231-246.

Wood, D. M. (1990). Soil behaviour and critical state soil mechanics. Cambridge: Cambridge University Press. 